University of Nebraska - Lincoln

DigitalCommons@University of Nebraska - Lincoln

Publications from USDA-ARS / UNL Faculty

U.S. Department of Agriculture: Agricultural

Research Service, Lincoln, Nebraska

2009

\title{
WUS and STM-based reporter genes for studying meristem development in poplar
}

\author{
Y. Bao \\ Oregon State University \\ P. Dharmawardhana \\ Oregon State University \\ R. S. Arias \\ U.S.D.A. National Peanut Res. Lab., renee.arias@usda.gov \\ M. B. Allen \\ Oregon State University \\ C. $\mathrm{Ma}$ \\ Oregon State University
}

See next page for additional authors

Follow this and additional works at: https://digitalcommons.unl.edu/usdaarsfacpub

Part of the Agricultural Science Commons

Bao, Y.; Dharmawardhana, P.; Arias, R. S.; Allen, M. B.; Ma, C.; and Strauss, Steven H., "WUS and STM-based reporter genes for studying meristem development in poplar" (2009). Publications from USDA-ARS / UNL Faculty. 900.

https://digitalcommons.unl.edu/usdaarsfacpub/900

This Article is brought to you for free and open access by the U.S. Department of Agriculture: Agricultural Research Service, Lincoln, Nebraska at DigitalCommons@University of Nebraska - Lincoln. It has been accepted for inclusion in Publications from USDA-ARS / UNL Faculty by an authorized administrator of DigitalCommons@University of Nebraska - Lincoln. 


\section{Authors}

Y. Bao, P. Dharmawardhana, R. S. Arias, M. B. Allen, C. Ma, and Steven H. Strauss

This article is available at DigitalCommons@University of Nebraska - Lincoln: https://digitalcommons.unl.edu/ usdaarsfacpub/900 


\title{
WUS and STM-based reporter genes for studying meristem development in poplar
}

\author{
Y. Bao $\cdot$ P. Dharmawardhana $\cdot$ R. Arias $\cdot$ M. B. Allen $\cdot$ \\ C. Ma $\cdot$ Steven H. Strauss
}

Received: 26 September 2008/Revised: 8 January 2009/Accepted: 8 February 2009/Published online: 12 March 2009

(C) Springer-Verlag 2009

\begin{abstract}
We describe the development of a reporter system for monitoring meristem initiation in poplar using promoters of poplar homologs to the meristem-active regulatory genes WUSCHEL (WUS) and SHOOTMERISTEMLESS $(S T M)$. When $\sim 3 \mathrm{~kb}$ of the $5^{\prime}$ flanking regions of close homologs were used to drive expression of the GUSPlus gene, $50-60 \%$ of the transgenic events showed expression in apical and axillary meristems. However, expression was also common in other organs, including in leaf veins (40 and $46 \%$ of WUS and STM transgenic events,
\end{abstract}

Communicated by S. Merkle.

Electronic supplementary material The online version of this article (doi:10.1007/s00299-009-0685-3) contains supplementary material, which is available to authorized users.

Y. Bao $\cdot$ P. Dharmawardhana $\cdot$ C. Ma $\cdot$ S. H. Strauss

Department of Forest Ecosystems and Society,

Oregon State University, Corvallis, OR 97331-5752, USA

Y. Bao $\cdot$ S. H. Strauss $(\square)$

Genetics Graduate Program, Oregon State University,

Corvallis, OR 97331-7303, USA

e-mail: steve.strauss@oregonstate.edu

Present Address:

P. Dharmawardhana

Department of Botany and Plant Pathology,

Oregon State University, Corvallis, OR 97331-2902, USA

Present Address:

R. Arias

Genomics Laboratory, USDA-ARS, Stoneville,

MS 38776-0038, USA

Present Address:

M. B. Allen

College of Pharmacy, Oregon State University,

Corvallis, OR 97331-3507, USA respectively) and hydathodes (56\% of WUS transgenic events). Histochemical GUS staining of explants during callogenesis and shoot regeneration using in vitro stems as explants showed that expression was detectable prior to visible shoot development, starting 3-15 days after explants were placed onto callus inducing medium. A minority of WUS and STM events also showed expression in the cambium, phloem, or xylem of regenerated, greenhouse grown plants undergoing secondary growth. Based on microarray gene expression data, a paralog of poplar WUS was detectably up-regulated during shoot initiation, but the other paralog was not. Both paralogs of poplar STM were downregulated threefold to sixfold during early callus initiation. We identified 15-35 copies of cytokinin response regulator binding motifs (ARR1AT) and one copy of the auxin response element (AuxRE) in both promoters. Several of the events recovered may be useful for studying the process of primary and secondary meristem development, including treatments intended to stimulate meristem development to promote clonal propagation and genetic transformation.

Keywords WUS - STM - Populus · Promoter ·

Meristem · Organogenesis

$\begin{array}{ll}\text { Abbreviations } \\ \text { ARR } & \text { Arabidopsis response regulator } \\ \text { AuxRE } & \text { Auxin response element } \\ \text { CIM } & \text { Callus induction medium } \\ C L V & \text { CLAVATA } \\ \text { CZ } & \text { Central zone } \\ \text { PLACE } & \text { Plant } \text { Cis-acting regulatory DNA elements } \\ \text { RAM } & \text { Root apical meristem } \\ \text { SAM } & \text { Shoot apical meristem } \\ \text { SAUR } & \text { Small auxin-up RNA } \\ \text { SIM } & \text { Shoot induction medium }\end{array}$




\section{STM SHOOTMERISTEMLESS}

SURE Sulfur-responsive element

TAIR The Arabidopsis information resource

VC Vascular cambium

WUS WUSCHEL

$\mathrm{X}$-Gluc 5-Bromo-4-chloro-3-indolyl- $\beta$-D-glucuronic acid

\section{Introduction}

Plant meristems consist of stem cells and rapidly dividing daughter cells with restricted development potential. The latter, often called as pluripotent stem cells, continue dividing to generate new cells for differentiation into different tissues and organs. Three major types of meristems that are generally recognized in plants are the apical meristem, the primary meristem, and the secondary meristem (Laux 2003; Scofield and Murray 2006). Apical meristems include completely undifferentiated stem cells; they are located at shoot tips and root tips, which are called shoot apical meristems (SAMs) and root apical meristems (RAMs), respectively. A small population of slowly dividing stem cells is located in the central zone $(\mathrm{CZ})$ in both the SAM and RAM that maintain stem cell identity. The analysis of meristem differentiation and structure, especially in Arabidopsis, has been the subject of numerous studies and recent reviews (Williams and Fletcher 2005; Vernoux and Benfey 2005; Bhalla and Singh 2006).

Among dozens of identified meristem regulatory factors, WUSCHEL (WUS) and SHOOTMERISTEMLESS (STM) are the two meristem-predominant genes whose function has been well studied. Approximately 240 research articles on these genes were cataloged in The Arabidopsis information resource (TAIR) in early 2008. The maintenance of the SAM in Arabidopsis is regulated by a feedback loop between WUS and CLAVATA (CLV) (Laux et al. 1996; Mayer et al. 1998). $W U S$ is expressed in the organizing center, and induces expression of $C L V 3$ - the hypothesized ligand for the CLV1 receptor kinase. When CLV1 interacts with CLV3, it triggers a signaling pathway which results in the repression of the expression of WUS. STM is a Class I knotted-like homeodomain protein required for SAM formation during embryogenesis and other points in plant development (Long et al. 1996). It functions by preventing the incorporation of cells from the meristem center into differentiating organ primordia. Organ development takes place when STM is down-regulated in primordial cells. The regulation of Arabidopsis root apical meristems (RAMs) have common themes with those of SAMs (Byrne et al. 2003).

Poplar shares the majority of its meristem regulatory framework with Arabidopsis, however, additional regulatory signaling networks appear to be present. For example, the Populus homologs of STM are expressed in both the SAM and the vascular cambium (VC) (Groover 2005; Groover et al. 2006). Populus WUS appears to be expressed only in the SAM, whereas WUS-like genes are expressed in the VC zone (Schrader et al. 2004). Examination of the expression patterns of WUS, STM and their related genes in poplar can help to reveal the specialized roles of the vascular cambium regulatory genes in woody plants, as well as to help identify the conserved themes of SAM and VC development.

The production and development of adventitious meristematic organs are considered to be the important limiting factors to vegetative propagation and transformation of plant species (Arias et al. 2006). To provide new tools to understand and modify meristem development, we created two new promoter::reporter systems based on the promoters of close Populus homologs of WUS and STM. We characterized the expression patterns of transgenic plants with these transgenes, and then analyzed the relation of their expression patterns to microarray studies of poplar development. The transgenic plants should also provide useful tools for further dissection of the factors that control meristem development in poplar.

\section{Materials and methods}

Plant material, transformation and regeneration

Hybrid poplar clone INRA 717-1 B4 (female, Populus tremula $\times P$. alba) was used for all transformation and microarray studies. The genome sequence of Populus trichocarpa Nisqually-1 (Tuskan et al. 2006) was used as a source to predict and amplify the WUS and STM promoters. Plants were in vitro propagated and transformed according to the protocol described by Filichkin et al. (2006). Fortyto 50-day-old plantlets served as explant sources.

Bioinformatic analysis of Populus homologs to WUS and $S T M$

The amino acid sequences of the Arabidopsis WUS (AT2G17950.1) and STM (AT1G62360.1) were retrieved from TAIR (http://www.Arabidopsis.org/index.jsp). The sequences were BLASTed against the database of poplar protein sequences at the Joint Genome Institute (http://genome.jgi-psf.org/Poptr1_1/Poptr1_1.home.html). Phylogenetic analysis was conducted using the NeighborJoining method in MEGA version 4 (Tamura et al. 2007). Tests of inferred phylogenetic groups were conducted by bootstrapping with 500 replications. Sequence alignments were done with MUSCLE at the Center for Genome Research and Biocomputing (CGRB) of Oregon State 
University (http://www.cgrb.oregonstate.edu/). EST information from the DFCI Poplar Gene Index (http://compbio. dfci.harvard.edu/tgi/cgi-bin/tgi/gimain.pl?gudb=poplar) was used to obtain evidence for expression in different tissue types for the putative Populus WUS and STM homologs. Cis-acting regulatory elements were identified by scanning the $3 \mathrm{~kb}$ of $5^{\prime}$ untranslated sequences against the Database of Plant Cis-acting Regulatory DNA Elements (PLACE, http://www.dna.affrc.go.jp/PLACE/index. html) (Higo et al. 1999).

\section{Construction of ProWUS::GUS and ProSTM::GUS constructs}

The 35S promoter driving GusPlus in pCAMBIA1305.1 was removed using HindIII and NcoI, blunt ended and selfligated. The HPTII gene was also removed from it as an XhoI fragment and replaced by NPTII using an XhoI fragment from pCAMBIA 2300. The resulting plasmid requires kanamycin as a selection agent both for plant and bacterial transformation, and has no promoter driving GusPlus. The resulting construct was called pPROTEST, and was used to help create the WUS and STM reporter constructs.

Based on phylogenetic analysis, grail3.0019031001 (http://genome.jgi-psf.org/Poptr1_1/Poptr1_1.home.html) was used as a target to amplify a poplar WUS promoter from $P$. trichocarpa genomic DNA using WUS2proForward, and WUS2proReverse primers (Table S1). The 3,492 nt fragment upstream from the WUS gene start codon was cloned into the pCR4-TOPO vector (Invitrogen) and sequenced using T7 and T3 promoters primers from outside of the promoter sequence, and also internal primers WUSpro1, WUSpro2, WUSpro3, WUSpro4, and WUSpro5 (Table S1).

estExt_Genewise1_v1.C_LG_II1820 was used as a target to amplify a poplar STM promoter using STM3pro-F03, and STM3pro-R01. The 3,320 nt fragment upstream from poplar STM start codon was cloned into pCR4-TOPO vector (Invitrogen) and sequenced using T7 and T3 promoter primers from outside of the promoter sequence, as well as the internal primers STMinternal\#1, STMinternal\#2, STMinternal\#3, STMinternal\#4, and STMinternal\#5 (Table S1).

For both genes, the forward and reverse primers contained an inserted SacI site at the $5^{\prime}$ end and a KpnI site at the $3^{\prime}$ end to allow directional cloning into the pPROTEST vector. DNA sequencing was used to verify the integrity of junction sequences. The constructs (Fig. 1; for complete maps, see Electronic Supplemental Materials S2, 3) were transferred to Agrobacterium strain AGL1, PCR confirmed, and transformed into hybrid poplar clone INRA 717-1B4 $(P$. tremula $\times P$. alba). WUS transgenic plants were confirmed by PCR amplification of a 1,580 bp product with primers WUSpro4 and GPLUS287R. STM transgenic plants were confirmed via PCR amplification of a $732 \mathrm{bp}$ product with primers KNX91F and GPLUS287R. PCR confirmed plants were also confirmed via GUS staining, as described below.

\section{Histochemical GUS staining}

For histochemical GUS staining, tissues of entire regenerated plants from Magenta boxes (roots and shoots) were incubated overnight in $2 \mathrm{mM}$ of 5-bromo-4-chloro-3indolyl- $\beta$-D-glucuronic acid (X-Gluc) solution at $37^{\circ} \mathrm{C}$ essentially as described (Weigel and Glazebrook 2002). After staining, whole plants were treated for $30 \mathrm{~min}$ in $10 \%$ aqueous solution of commercial bleach $(5.25 \%$ sodium hypochlorite), transferred to $70 \%$ ethanol, and photographed using an Olympus C5050 digital camera. Individual plant organs were examined and photographed using Zeiss Stemi SV 11 dissection microscope (Carl Zeiss Microimaging, Inc., Thornwood, NY).

For study of reporter gene expression during in vitro organogenesis, we selected a single transgenic event from each construct that showed strong meristematic expression (PopWUS1 event 47 and PopSTM1 event 130), and then used the same time points for collecting explants as had been used in our microarray studies (Bao 2008). These were at 3 and 15 days on callus induction medium (CIM), and 3 and 8 days on shoot induction medium (SIM). To study expression in the vascular cambium, 12 WUS events and 13 STM events were transferred into soil and grown for approximately 100 days, until the transplanted trees were healthy and approximately $0.75 \mathrm{~m}$ in height. GUS staining was done as above, on two ramets from each event. Stem sections were taken by hand from internodes $\sim 4 \mathrm{~cm}$ above the soil.

Microarray analysis

An Affymetrix GeneChip ${ }^{\circledR}$ Poplar Genome Array was used to analyze the expression of poplar WUS, STM and closely

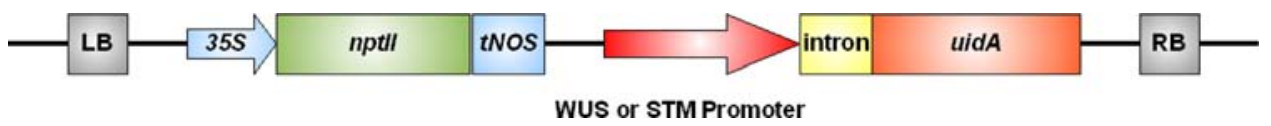

Fig. 1 Schematic representations of ProWUS::GUSPlus and ProS$T M:: G U S P l u s$ vectors. $L B$ and $R B$ left and right T-DNA borders, respectively; tNOS: nopaline synthase terminator; nptII: neomycin phosphotransferase II; uidA: gusPlus reporter gene containing an intron. Diagram is not drawn to scale 
related genes during in vitro shoot organogenesis. Sample collection, RNA extraction, probe labeling and hybridization, and quantitative analysis were described in Bao (2008). In brief, RNAs were extracted separately from two batches (biologic replications) that had been grown under the same growth conditions but 3 weeks apart in February 2007. For both replications, samples were collected at five time points: prior to callus induction, 3 days on CIM, 15 days on CIM (then transferred to SIM), and 3 and 8 days on SIM. Approximately, 10-15 stem explants from the same plate $(\sim 3-4 \mathrm{~mm}$ in length, with nodes removed) were pooled for RNA extraction for each biologic replication. The arrays were labeled and hybridized according to Affymetrix protocols, and the summary value extracted for each gene was based on a $\log 2$ scale.

Tissue type microarray data were extracted from a dataset (Brunner et al. 2007) generated using a poplar Nimblegen microarray (http://www.nimblegen.com/), and targeting 55,794 predicted transcripts from the Populus trichocarpa genome sequencing project, 126 mitochondrial and chloroplast gene models, and 9,995 unigenes derived from aspen EST sequences (Sterky et al. 2004). Each gene model was represented by three replicated $60 \mathrm{mer}$ isothermal probes on the array. Array hybridization, quality control, and data extraction were carried out by Nimblegen using their established microarray processing pipeline (Wang et al. 2006). Microarray data were normalized across all the arrays used in the experiment using the Bioconductor-Robust Multiarray Averaging (RMA) protocol.

For analysis of microarray expression of the poplar WUS, STM, and related genes, their coding sequences were submitted to the Affymetrix NetAffx Analysis Center (http://www.affymetrix.com/analysis/index.affx) to search for the probe sets targeting those genes (Table S7). The expression for a probe set on a single array is estimated by the signal intensities detected from 11 distinct probes randomly located on the array. Not all genes have a corresponding probe set with 11 perfectly matching probes on the array. Only probe sets with at least half of the 11 probes targeting the gene were used to estimate the expression of the genes in our study.

For $W U S$ and its related genes, the signal intensity from PtpAffx.207414.1.S1_at was used to estimate the expression of PopWUS1. It targeted the less conserved region of PopWUS1 (alignment not shown). PtpAffx.54684.1.A1_at, targeting the less conserved region of PopWUS2, was used for study of PopWUS2. PtpAffx.218777.1.S1_s_at targeted the conserved region of PopWUS1 and PopWUS2, and gw1.21516.1.1. As a result, the signal intensity from
Fig. 2 Analysis of the amino acid sequences of the putative Populus WUS encoding genes and their relationship to Arabidopsis WUS. a

Phylogenetic analysis of Arabidopsis WUS and its homologs in poplar.

Bootstrapping values (\%) are based on 500 replications. grail3.0019031001 was used for promoter studies. b Alignment of the amino acid sequences of Arabidopsis WUS and its homologs in poplar. The signature domains of the WUS homeodomain and WUS box are indicated

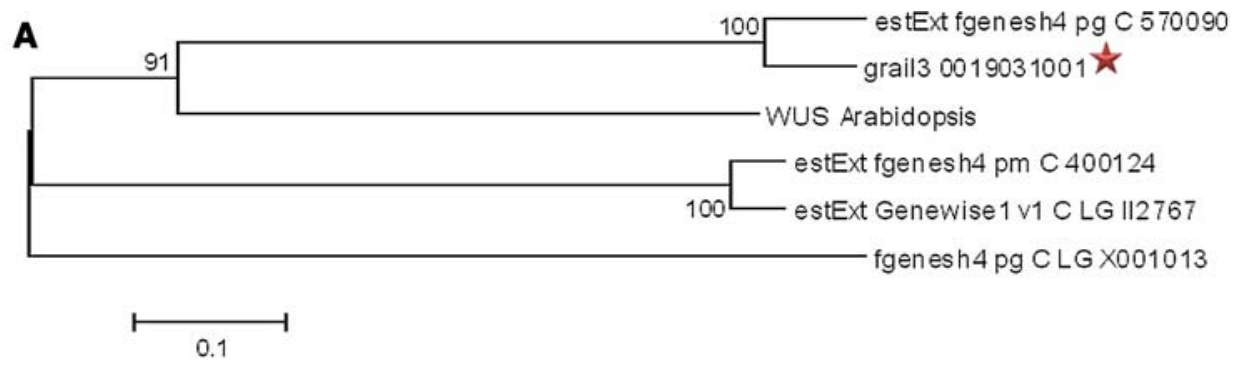

B

Homeodomain

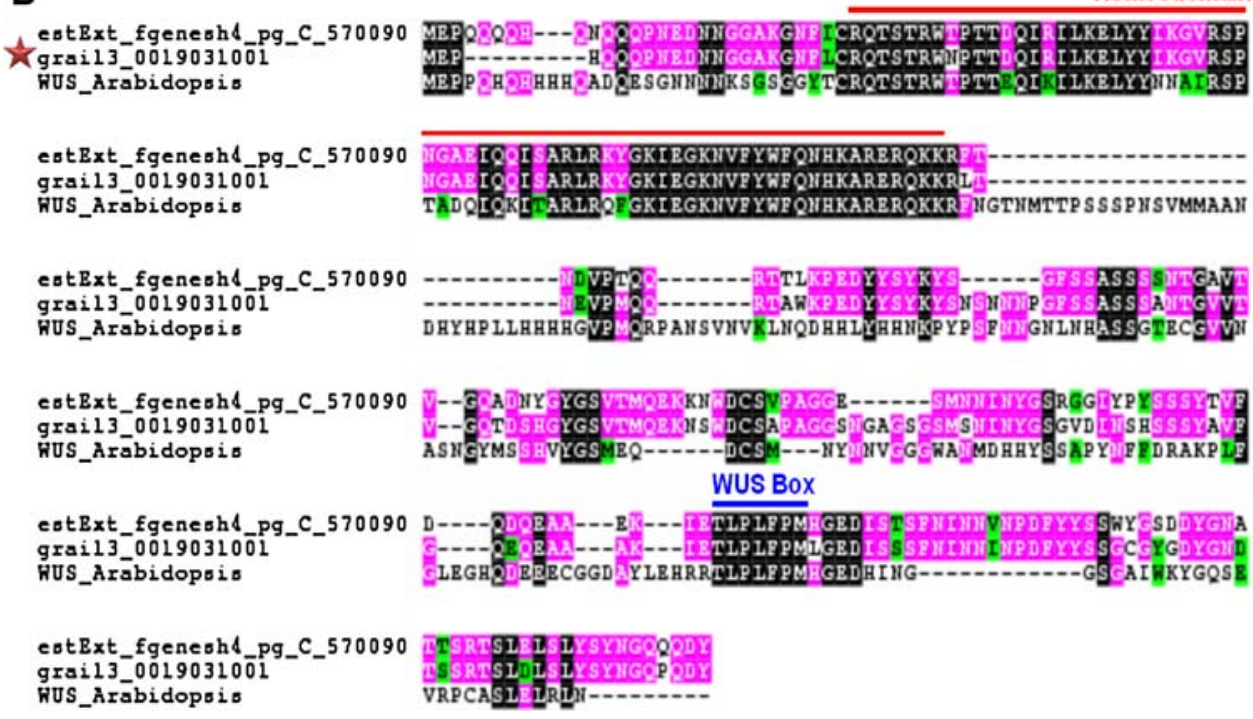


Fig. 3 Analysis of the amino acid sequences of the putative Populus STM encoding genes and their relationship to Arabidopsis STM. a Phylogenetic analysis of Arabidopsis STM and its Populus homologs. Bootstrapping values (\%) are based on 500 replications. b Alignment of the amino acid sequences of Arabidopsis STM and Populus homologs. estExt_Genewise1_v1.C_LG_ II1820 was used for promoter analysis. The signature motifs of STM, KNOX1, KNOX2, ELK and homeodomain are indicated
A

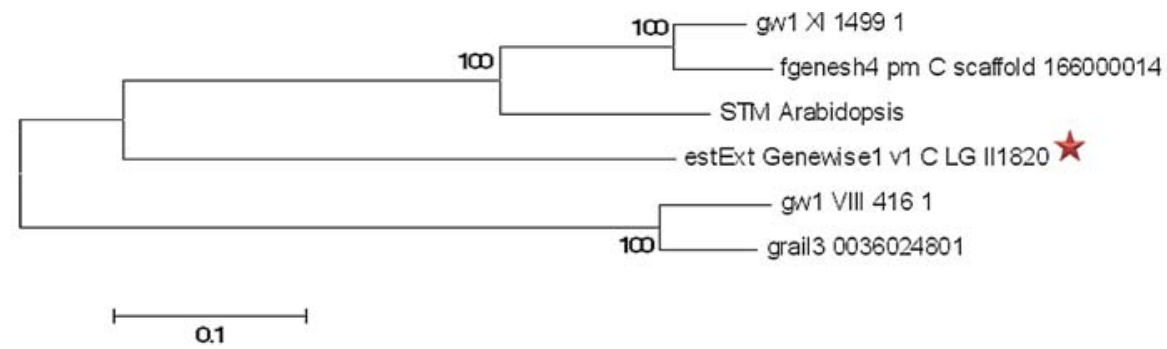

B

STM_Arabidopaio geñeoh4_pm_C_ocaffold_166000014 $g \times 1 \times 1$

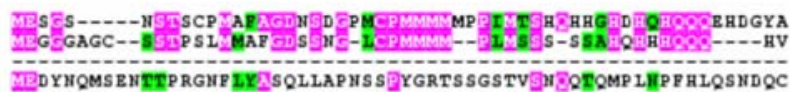

STM_Arabidopsio
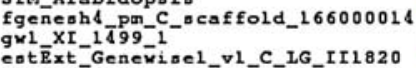
fgeneoh4 $\mathrm{pm}-\mathrm{C}$

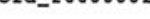

ent $\bar{B} \times t$ Generisel_v1_C_LG_II1820

STM_Arabidopsio

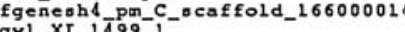
gu1 XI_1499-1

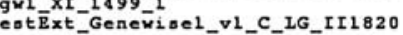

STM_Arabidopsis

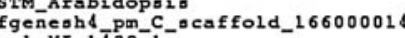

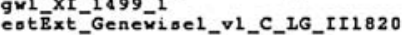

STM_Arabidopsio

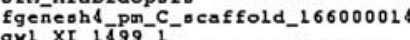
gu1 XI-1499-1

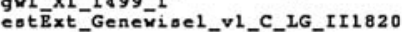

STM_Arabidopoi。 ggenesh4 4 proc

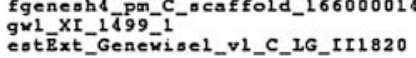
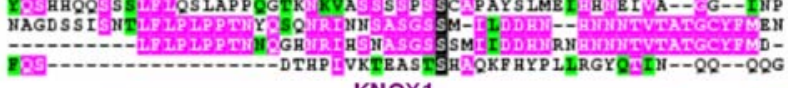
KNOX1

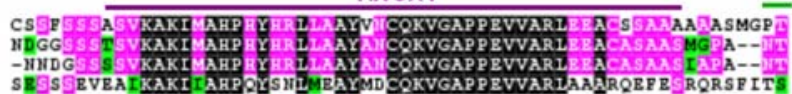
$\mathrm{KNO} 2$

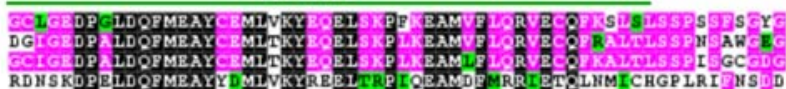
ELK

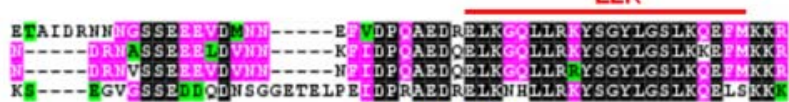
Homeodomain
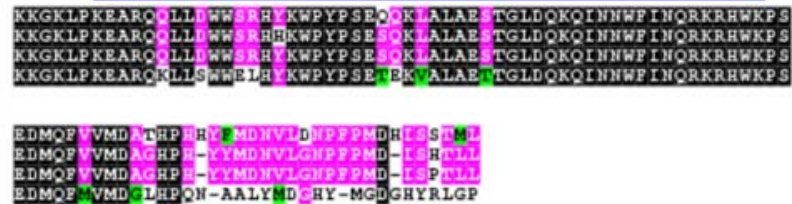

Table 1 Summary of expression patterns of PopWUS1::GUSPlus transgenic events

\begin{tabular}{|c|c|c|c|c|c|c|c|}
\hline \multirow{2}{*}{$\begin{array}{l}\text { Populus WUS } \\
45 \text { events }\end{array}$} & \multirow{2}{*}{$\begin{array}{l}\text { Apical and axillary } \\
\text { meristems }\end{array}$} & \multicolumn{4}{|l|}{ Other aerial } & \multicolumn{2}{|l|}{ Subaerial } \\
\hline & & Hydathodes & $\begin{array}{l}\text { Leaf lamina } \\
\text { and veins }\end{array}$ & $\begin{array}{l}\text { Leaf lamina } \\
\text { and petioles }\end{array}$ & Stipules & Root tips & Others \\
\hline Number of events & 21 & 25 & 18 & 5 & 9 & 4 & 7 \\
\hline$\%$ & 46.7 & 55.6 & 40.0 & 11.1 & 20.0 & 8.9 & 15.6 \\
\hline Photograph (Fig. 4) & $\mathrm{a}$ & $\mathrm{b}$ & $\mathrm{c}$ & $\mathrm{d}$ & $\mathrm{e}$ & $\mathrm{f}$ & $\mathrm{g}$ \\
\hline
\end{tabular}

All PCR positive PopWUS1::GUSPlus transgenic events were GUS stained. The numbers of events and percentages of the type of tissues in which GUS was expressed are presented; photographic examples are given in Fig. 4

PtpAffx.218777.1.S1_s_at reflected the expression of all three genes. For STM, only PopSTM1 and grail3.0036024801 are detectable on the array (among STM and its related genes only these two have more than seven matching probes in their corresponding probe sets).

\section{Results}

Development of WUS- and STM-based reporter genes

To identify Populus homologs of WUS and STM that are expressed in meristems, we searched the JGI Populus
(Populus trichocarpa v1.1) genome database using the Arabidopsis WUS and STM amino acid sequences as query sequences, respectively. The 291 amino acids (aa) encoded by the WUS gene consists of two conserved domains, a 66 aa homeodomain and an 8 aa WUS Box (TLPLFPMH) located downstream of the homeodomain (Haecker et al. 2004; Mayer et al. 1998). The top five BLAST genes that had complete open reading frames were subject to further phylogenetic analysis. Three of these gene models, gw1.21516.1.1, gw1.XII.25.1, and gw1.XV.1017.1, contained the conserved homeodomain regions; they appeared to be truncated upstream of the conserved regions and thus were not considered as promoter candidates (data not 
Fig. 4 Expression patterns of ProWUS::GUSPlus transgenic events. Examples of GUS expression in a apical and axillary meristems,

b hydathodes, $\mathbf{c}$ major leaf veins and edges, $\mathbf{d}$ leaf veins and petiole, e stipules, f root tips, g root tissues. Arrows indicate the locations of prominent expression. Scale bars $4 \mathrm{~mm}$
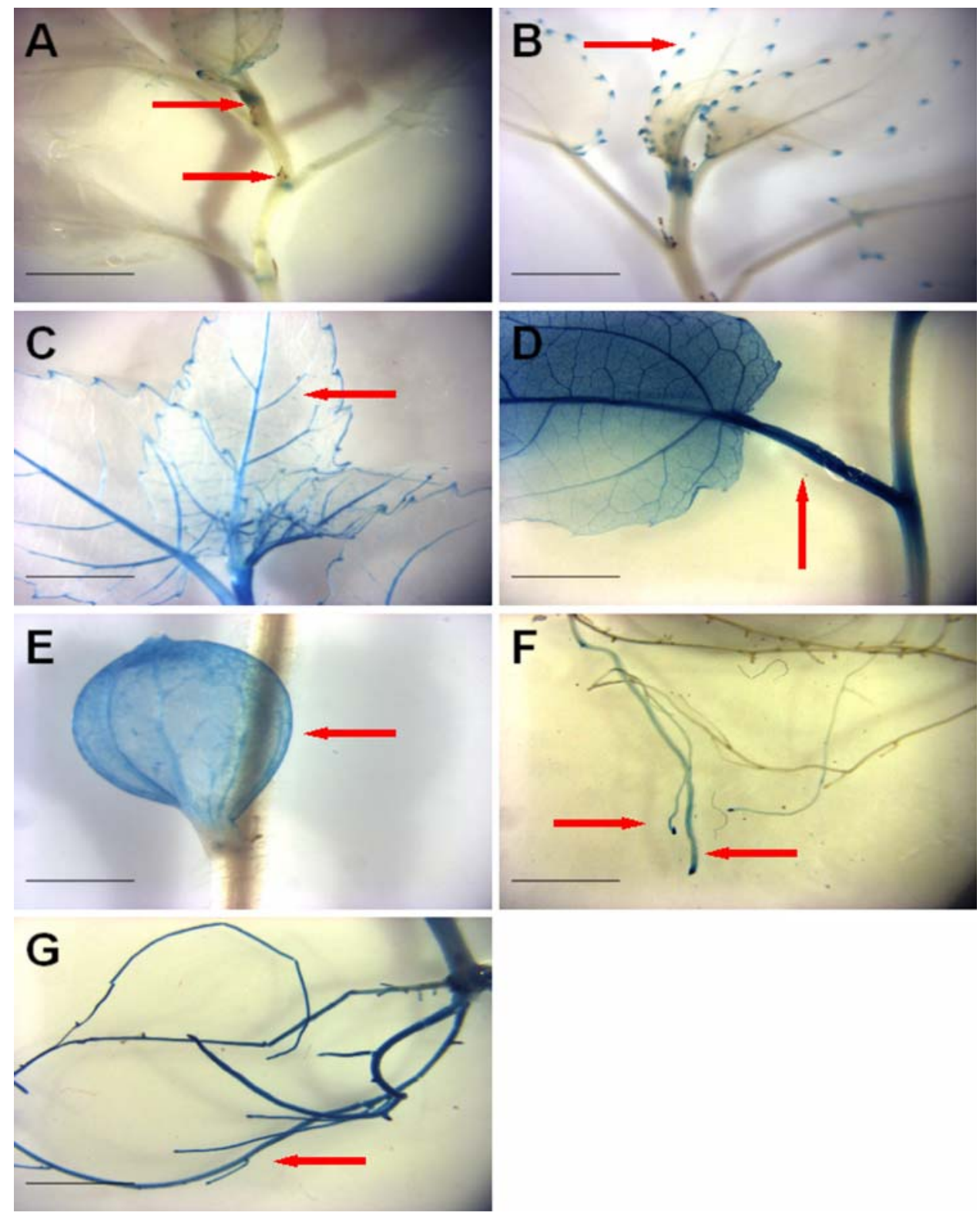

shown). Two poplar genes, grail3_0019031001 and estExt_fgenesh4_pg_C_570090 (hereafter called PopWUS1 and PopWUS2, respectively), were most closely related to Arabidopsis WUS (Fig. 2a). These two genes are highly similar, sharing $79 \%$ identity and $87 \%$ similarity in amino acid sequences. Bootstrapping showed $100 \%$ replication of their close association, and a strong association with Arabidopsis WUS (above 90\%). The identity of these two genes and Arabidopsis WUS is approximately 40\%, and their similarity $63 \%$. Alignment of their amino acid sequences showed that both poplar paralogs of WUS have the highly conserved homeodomain and WUS Box (Fig. 2b), but also are differentiated by a considerable number of amino acid indels in otherwise conserved areas.
The Arabidopsis WUS gene has three exons and two introns. The lengths of the exons are 620,88 , and $516 \mathrm{bp}$, and the introns are 601 and $90 \mathrm{bp}$, respectively. PopWUS1 and PopWUS2 also have three exons and two introns, but two of the three exons are shorter. The lengths of the exons of PopWUS1 are 364, 104, and 310 bp, respectively. PopWUS2 and PopWUS1 have very similar exon sizes. When searching the EST database, both PopWUS1 and PopWUS2 had high identity with ESTs TC60159, TC50140, TC49749, and TC76257, which were from cDNA libraries made from male catkins, flowers, bark, cambium, and apical shoots. Because of variation among the different Populus species in EST sequences, we could not determine which ESTs corresponded to PopWUS1 versus PopWUS2. As cited above, 
Fig. 5 Expression patterns of Populus ProSTM::GUSPlus events. GUS expression in a apical and axillary meristems; b hydathodes; c leaf lamina, veins, and petioles; $\mathbf{d}$ stipules; e root tips; $f$ other root tissues. Arrows indicate the expression locations. Scale bars $4 \mathrm{~mm}$
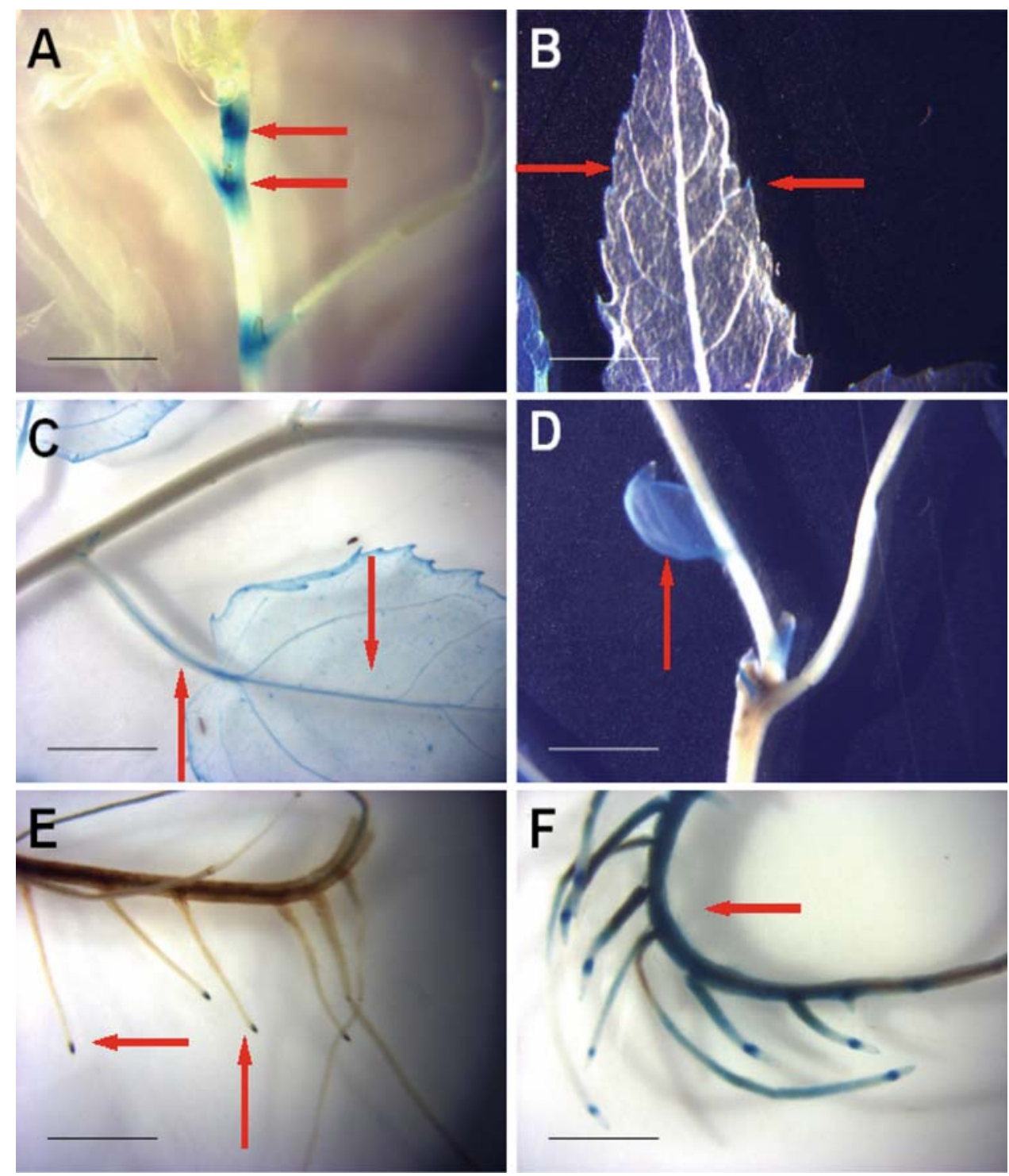

only grail3_0019031001 (PopWUS1) was selected for promoter analysis.

The Arabidopsis STM encodes a class I knotted-like protein that is 382 amino acid long (Long et al. 1996). The conserved domains of STM consist of KNOX, ELK and homeodomains. Five poplar genes with the highest BLAST scores were subject to phylogenetic analysis. As shown in Fig. 3a, gw1_XI_1499_1 and fgenesh4_pm_C_scaffold_166000014 are in the same clade with Arabidopsis STM, with a bootstrapping value of $100 \%$. estExt_ Genewise1_v1_C_LG_II1820 is also closely related to Arabidopsis STM, with a $100 \%$ bootstrapping value compared to the two other poplar STM genes. All of these poplar genes share the highly conserved KNOX1, KNOX2, ELK, and homeodomains with Arabidopsis STM, however, gw1_XI_1499_1 is truncated at the $5^{\prime}$ end and thus was not considered for promoter selection. We hereafter refer to estExt_Genewise1_v1_C_LG_II1820 and fgenesh4_
pm_C_scaffold_166000014 as PopSTM1 and PopSTM2, respectively.

Arabidopsis STM has three large introns, ranging in size from 460 to $690 \mathrm{bp}$. The sizes of its four exons range from 254 to 429 bp. PopSTM1 and PopSTM2 also have four exons, ranging from 205 to 419 bp. PopSTM1 has $99.9 \%$ identity with a 1,107-long EST (TC29178) derived from cDNA libraries of cambium, apical shoots, tension wood, and secondary xylem. PopSTM2 had $86 \%$ identity with a 1,124-long EST (NP1274762) which was found in secondary xylem. Based on its broader and less xylemdominant EST pattern, and similar phylogenetic profile to fgenesh4_pm_C_scaffold_166000014 (PopSTM2), we chose estExt_Genewise1_v1_C_LG_II1820 (PopSTM1) for our promoter studies.

A total of 45 PopWUS1 and 54 PopSTM1 independently regenerated, kanamycin-resistant events were PCR-positive (ESM S4). Based on the number of independent 
Table 2 Summary of expression patterns of PopSTM1::GUSPlus events

\begin{tabular}{|c|c|c|c|c|c|c|c|}
\hline \multirow{2}{*}{$\begin{array}{l}\text { Populus STM } \\
54 \text { events }\end{array}$} & \multirow{2}{*}{$\begin{array}{l}\text { Apical and axillary } \\
\text { meristems }\end{array}$} & \multicolumn{4}{|l|}{ Other aerial } & \multicolumn{2}{|l|}{ Subaerial } \\
\hline & & Hydathodes & $\begin{array}{l}\text { Leaf lamina } \\
\text { and veins }\end{array}$ & $\begin{array}{l}\text { Leaf lamina } \\
\text { and petioles }\end{array}$ & Stipules & Root tips & Others \\
\hline Number of events & 35 & 5 & 25 & 9 & 6 & 12 & 14 \\
\hline$\%$ & 64.8 & 9.3 & 46.3 & 16.7 & 11.1 & 22.2 & 25.9 \\
\hline Photograph (Fig. 5) & $\mathrm{a}$ & $\mathrm{b}$ & $\mathrm{c}$ & $\mathrm{d}$ & $\mathrm{e}$ & $\mathrm{e}$ & $\mathrm{f}$ \\
\hline
\end{tabular}

All PCR positive PopSTM1::GUSPlus transgenic events were GUS stained. The numbers of events and percentages of the type of tissues in which GUS was expressed are presented; photographic examples are given in Fig. 5

Fig. 6 GUS staining of recovered transgenic explants. A single PopWUS1::GUSPlus event (left panel), PopSTM1::GUSPlus event (middle panel), and control 717 (right panel) during in vitro regeneration. The five sequential time points used were: before transfer to callus induction medium (CIM), 3 days on CIM, 15 days on CIM, 3 days on shoot induction medium (SIM), and 8 days on SIM. Arrows in 8 days point to areas of intense GUS staining that represent putative areas of shoot meristem initiation. Scale bars $2 \mathrm{~mm}$
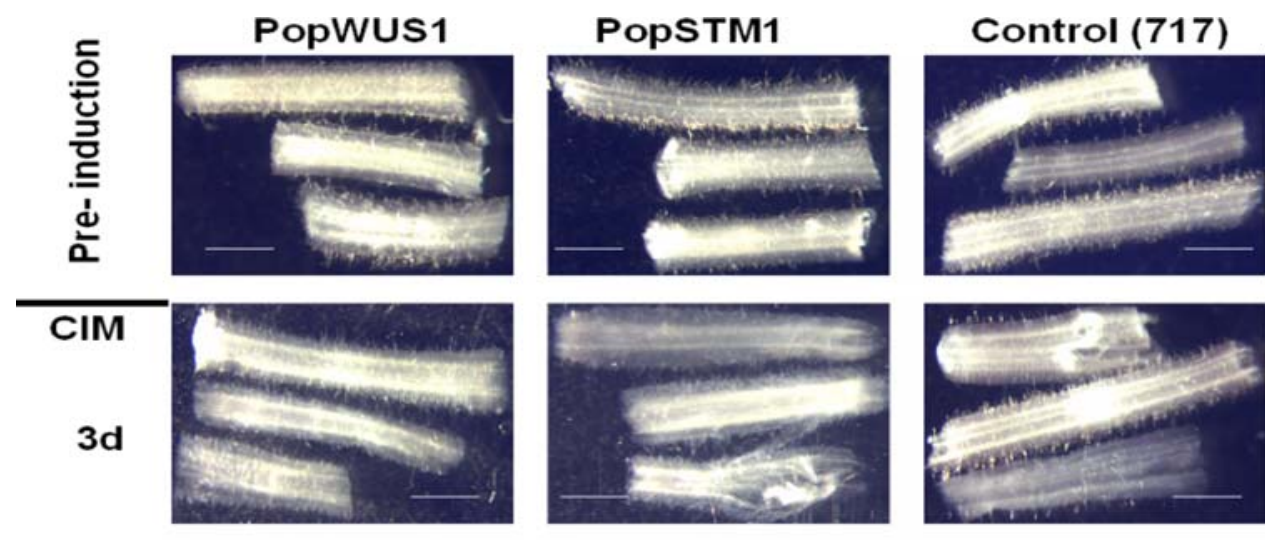

15d
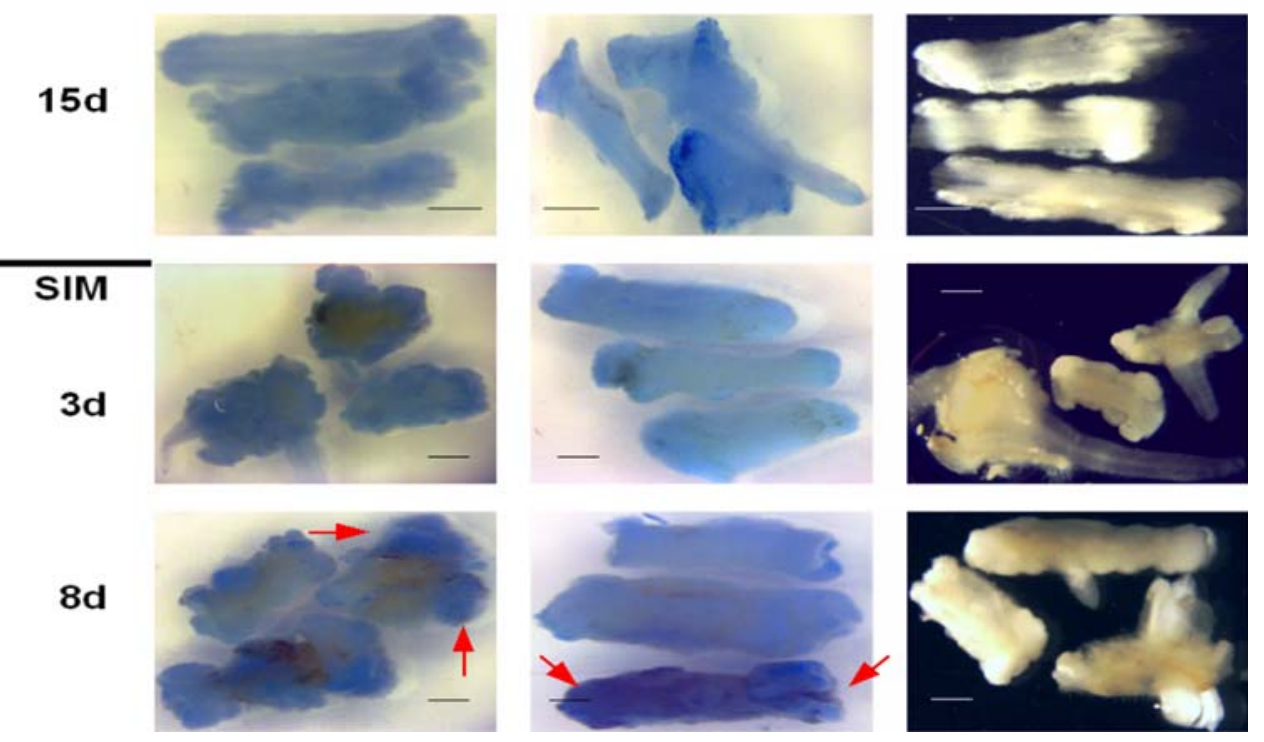

transgenic regenerants produced and compared to explants cocultivated, the transformation efficiency for both constructs was approximately $2.5 \%$.

Expression patterns conferred by WUS and STM promoters

To study tissue-specific expression, we performed histochemical GUS staining of all PCR-positive events.
Transformants for both genes showed a great diversity of expression patterns. Of 45 PopWUS1 transgenic events, GUS expression was detected in nearly all major types of tissues (Table 1; Fig. 4). Approximately, half (47\%) of the events had GUS expression in apical and axillary meristems (Fig. 4a). A large number also had expression in putative hydathodes $(56 \%$, Fig. $4 \mathrm{~b})$ and in leaf lamina and veins (40\%, Fig. 4c). We found only three events with exclusive expression in apical and axillary meristems, but 
Fig. 7 GUS expression patterns of WUS and STM transgenic events. A single PopWUS1:: GUSPlus event (left panel, a-c) and PopSTM1::GUSPlus event (d-e, right panel) after in vitro regeneration. a-c

PopWUS1::GUSPlus event GUS expression in a the whole plant; b apical and axillary meristem; c stem. $\mathbf{d}-\mathbf{f}$

PopSTM1::GUSPlus event GUS expression in $\mathbf{d}$ the whole plant; e apical and axillary meristem and hydathodes; and $\mathbf{f}$ in leaves. Scale bars $4 \mathrm{~mm}$

\section{PopWUS1}
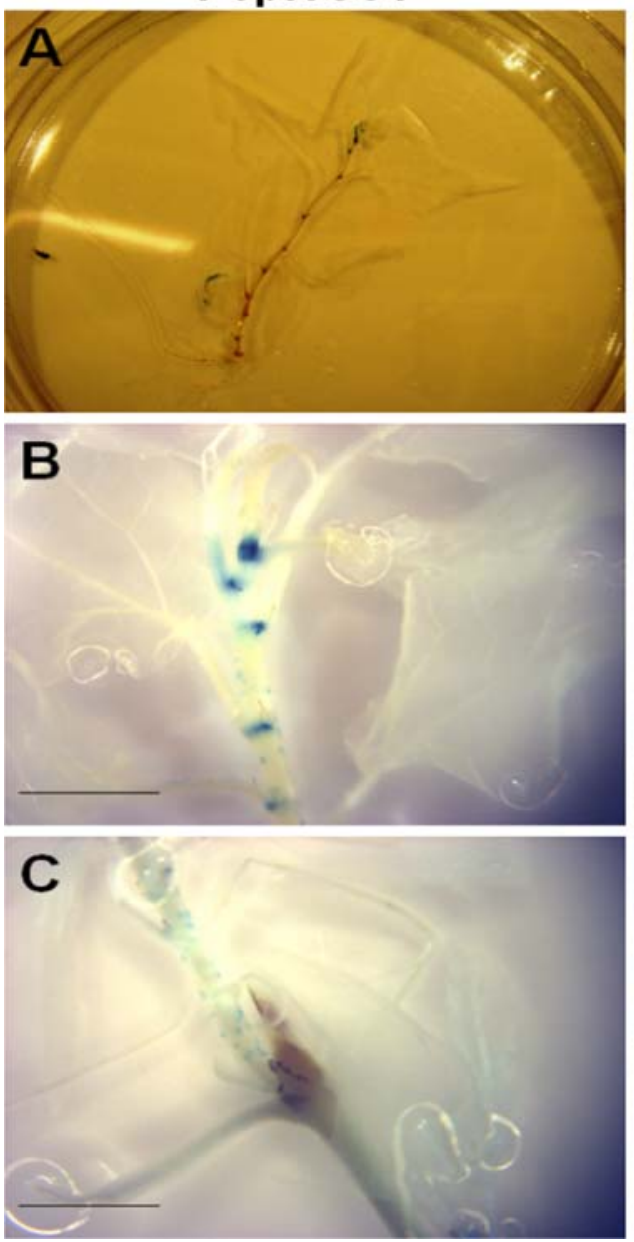

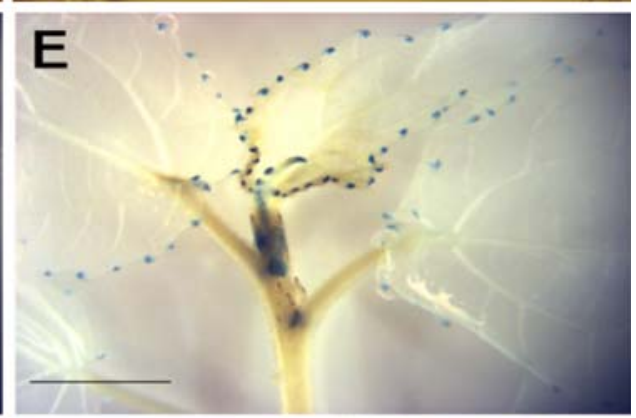

PopSTM1
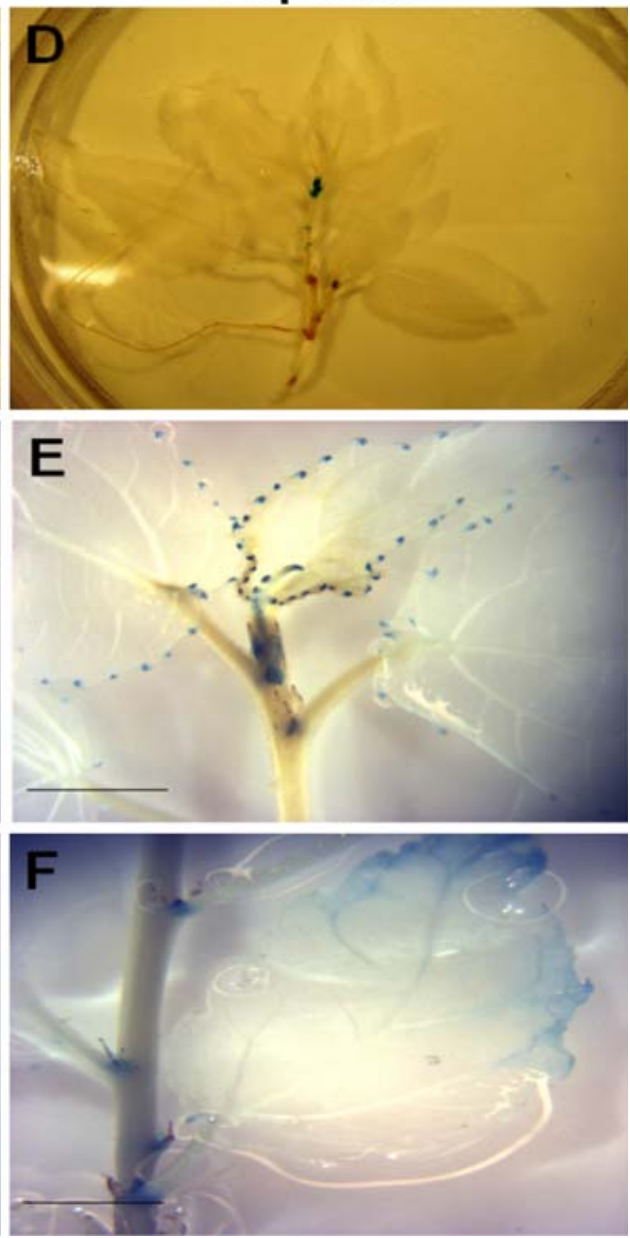

their expression was very weak (ESM S5). Over $80 \%$ of the events with expression in meristems also had expression in putative hydathodes.

Compared with PopWUS1 transgenic events, PopSTM1 transgenic events had a higher percentage of events with expression in meristems (65\% of 54 events, Fig. 5a) and leaf lamina and veins (46\%) (Table 2; Fig. 5c). We detected GUS expression in putative hydathodes in only 9\% (Fig. 5b) of transgenic events. Similar to PopWUS1, the events showed a great diversity of expression patterns. Eleven events had exclusive expression in meristems (20.4\%), but the expression level of all these events was low (ESM S6).

\section{Reporter expression during in vitro shoot organogenesis}

We chose a single transgenic event from both PopWUS1 and PopSTM1 and performed GUS staining at several stages during in vitro shoot organogenesis. The two events were chosen based on the observation that they showed strong and predominant meristem expression (PopWUS1 event 47 as seen in Fig. 7a and PopSTM1 event 130 as seen in Fig. 7d). No GUS expression was detected in the nontransgenic 717 controls (Fig. 6). In PopWUS1 and PopS$T M 1$, expression was detectable prior to visible shoot development, starting 3-15 days after explants were placed onto callus inducing medium (Fig. 6 CIM 15 days). GUS expression grew increasingly strong in calli over time, especially at the places where shoots tend to emerge (Fig. 6 SIM 3 and 8 days).

In regenerated plants, expression in apical and axillary meristems was still dominant (Fig. 7a, b, d), but GUS expression was also clearly detected in putative hydathodes in PopSTM1 transformants (Fig. 7e). We also observed low GUS expression in stems of PopWUS1 transformants, and in older leaves of PopSTM1 transformants. In the transplanted events growing in the greenhouse, only one WUS event showed GUS expression in both ramets, whereas four STM events showed GUS expression in stems of both ramets, of which one was in maturing xylem and three were predominantly in the phloem/cambium (Fig. 8). 
Fig. 8 Expression in stem sections of transgenic plants growing in the greenhouse that showed evidence of histochemical expression. Of 12 WUS::GUS events, only one event showed expression (a); of 13 STM::GUS events, only four events showed expression (b-d). b shows the stem of one event, and $\mathbf{c}$ shows stems of three events; the inset in $\mathbf{c}$ is magnified in $\mathbf{d}$. Scale bars $2 \mathrm{~mm}$
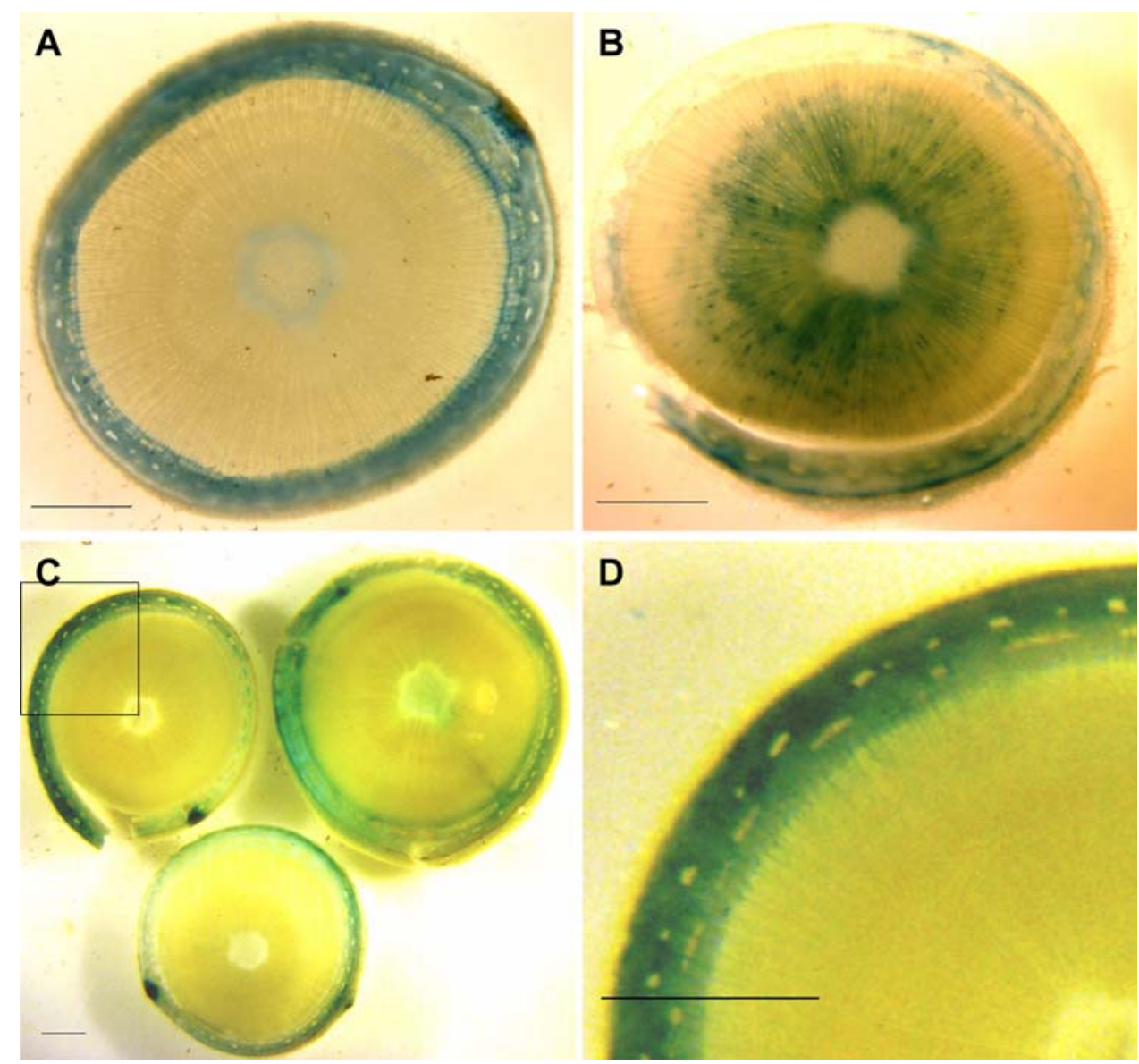

Microarray analysis of gene family expression

We retrieved gene expression estimates of all close homologs of poplar WUS and STM genes from two related microarray studies. The first microarray study was designed to analyze the genome scale transcriptome of shoot organogenesis which was represented by five time points: prior to induction, 3 and 8 days callus induction, 3 and 8 days shoot induction. The other microarray study was an analysis of tissue-specific expression of poplar genes using a NimbleGen custom microarray that was described under methods. For the latter study, most sample tissues were collected from 2-year-old poplar trees in the field.

The expression of PopWUS1, PopWUS2, and two other related genes could be detected by unique probe sets on the Affymetrix microarray. Due to low expression, PopWUS1 and fgenesh4_pg.C_LG_X001013 did not showed detectable changes during regeneration (Fig. 9a). PopWUS2 and possibly gw1.21516.1.1 were up-regulated sevenfold during the first 8 days of shoot induction. estExt_fgenesh4_ pm.C_400124 was down-regulated by more than tenfold change during late callus induction, and then up-regulated to the level prior to hormone treatment during the first
3 days of shoot induction. In the tissue type expression array study, PopWUS1 and PopWUS2 were still below the detection level in nearly all types of tissues; PopWUS1 was only detectable in catkins. However, estExt_fgenesh4_pm. C_400124 and estExt_Genewise1_v1.C_LG_II2767 had very high expression in phloem/cambium compared with both than in other tissues, and that of other WUS genes (Fig. 10a).

Only PopSTM1 and grail3.0036024801 were detectable on the Affymetrix microarray. Both of them were downregulated upon callus induction threefold and sixfold, respectively (Fig. 9b). The tissue-specific expression results showed that PopSTM1 was distinct from all other paralogs in having its highest expression in both apical and axillary buds, and in phloem/cambium (Fig. 10b).

Promoter motifs related to meristem regulation of WUS and STM

To test if WUS and STM in both Arabidopsis and poplar have similar cis-acting regulatory elements, we analyzed their promoter sequences. The $3 \mathrm{~kb}$ upstream sequences of WUS and STM in Arabidopsis, PopWUS1, PopWUS2, PopSTM1, and PopSTM2 were submitted to the PLACE. 
Fig. 9 Expression of poplar $W U S, S T M$ and closely related genes during in vitro shoot organogenesis. RNAs for micorarray were extracted from (Fig. 6 and "Methods"). The logarithms of intensities detected from hybridizations, after normalization, are plotted the explants at five time points
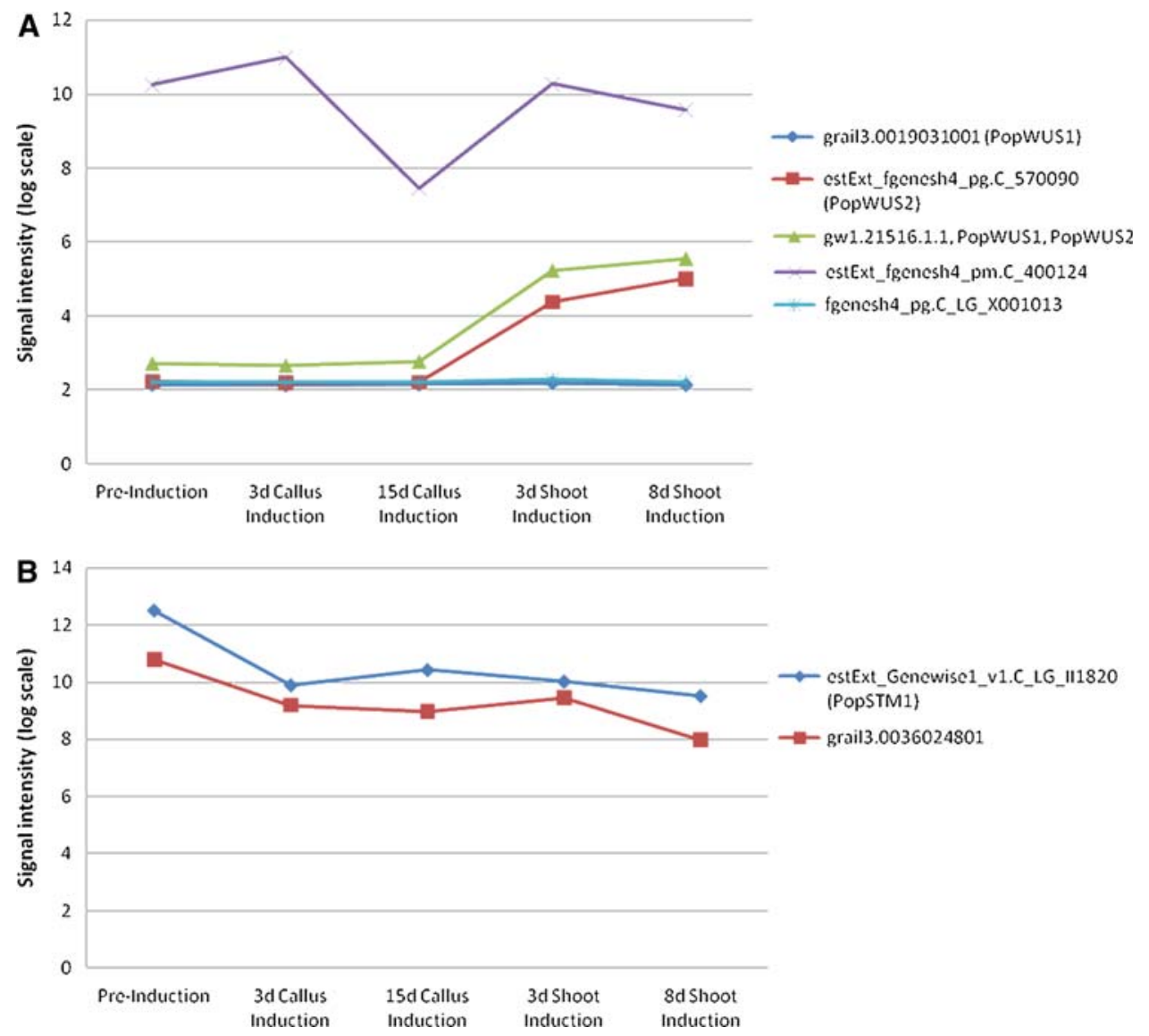

Special attention was paid to auxin and cytokinin related motifs, since the ratio of these two hormones directs the developmental fates of cells during shoot organogenesis.

Approximately, 800 motifs were identified for each gene; two motifs were related to cytokinin response, and three motifs to auxin response (Table 3). The distribution of hormone-associated motifs is shown in Fig. 11 and listed in Table 4. Our analysis shows that ARR1ATs are abundantly present in both strands of the promoters; their numbers ranged from 17 to 45 (Table 4). One to two copies of auxin response element (AuxRE) were also identified.

\section{Discussion}

The gene expression results from our microarray datasets, and the diversity of expression from WUS and STM promoters, suggests that expression of WUS and STM may be more complex in poplar than it is in Arabidopsis. A great diversity of expression has also been reported in rice transformed with a WUS-like gene driving GUS (Kamiya et al. 2003). Due to the large salicoid duplication in poplar, many single-copy genes in Arabidopsis have two close homologs in poplar, and many of these duplicated genes appear to have undergone subfunctionalization (Jansson and Douglas 2007). For example, STM is expressed in both apical meristem and secondary meristems in poplar (Groover 2005).

Our regeneration microarray study gave the initially surprising result that STM and its related genes were more highly expressed in stems than in the tissues undergoing shoot organogenesis. In addition, our primary STM paralog (PopSTM1) had its highest expression in phloem/cambium, xylem, and roots in 2-year-old trees from the field. For $W U S$, at least one paralog was up-regulated during shoot induction, despite very low expression during callus induction. Similar results were also reported in Arabidopsis (Che et al. 2006). However, the cloned paralog of WUS was undetectable in most tissues of adult trees, while three other WUS-like genes were highly expressed either in phloem/cambium, roots, catkins, xylem, and other tissues.

We identified a single copy of AuxRE and multiple copies of response regulator binding motifs (ARR1AT) (Ross et al. 2004) in both the WUS and STM promoters, and both in Arabidopsis and poplar. ARR1AT binds to Arabidopsis response regulator 1 (ARR1), which has an activation domain and serves as a type-B response regulator involved in cytokinin signaling (Ross et al. 2004). CPBCSPOR is found in the promoter of the cucumber (CS) POR (NADPH-protochlorophyllide reductase) gene, and is 
Fig. 10 Microarry analysis of tissue-specific expression of poplar WUS, STM, and closely related genes. Different types of tissues collected from field- or in vitro-grown plants were analyzed by a NimbleGen genome scale microarray. Genes with a normalized intensity $<0.8$ were not significantly different from background
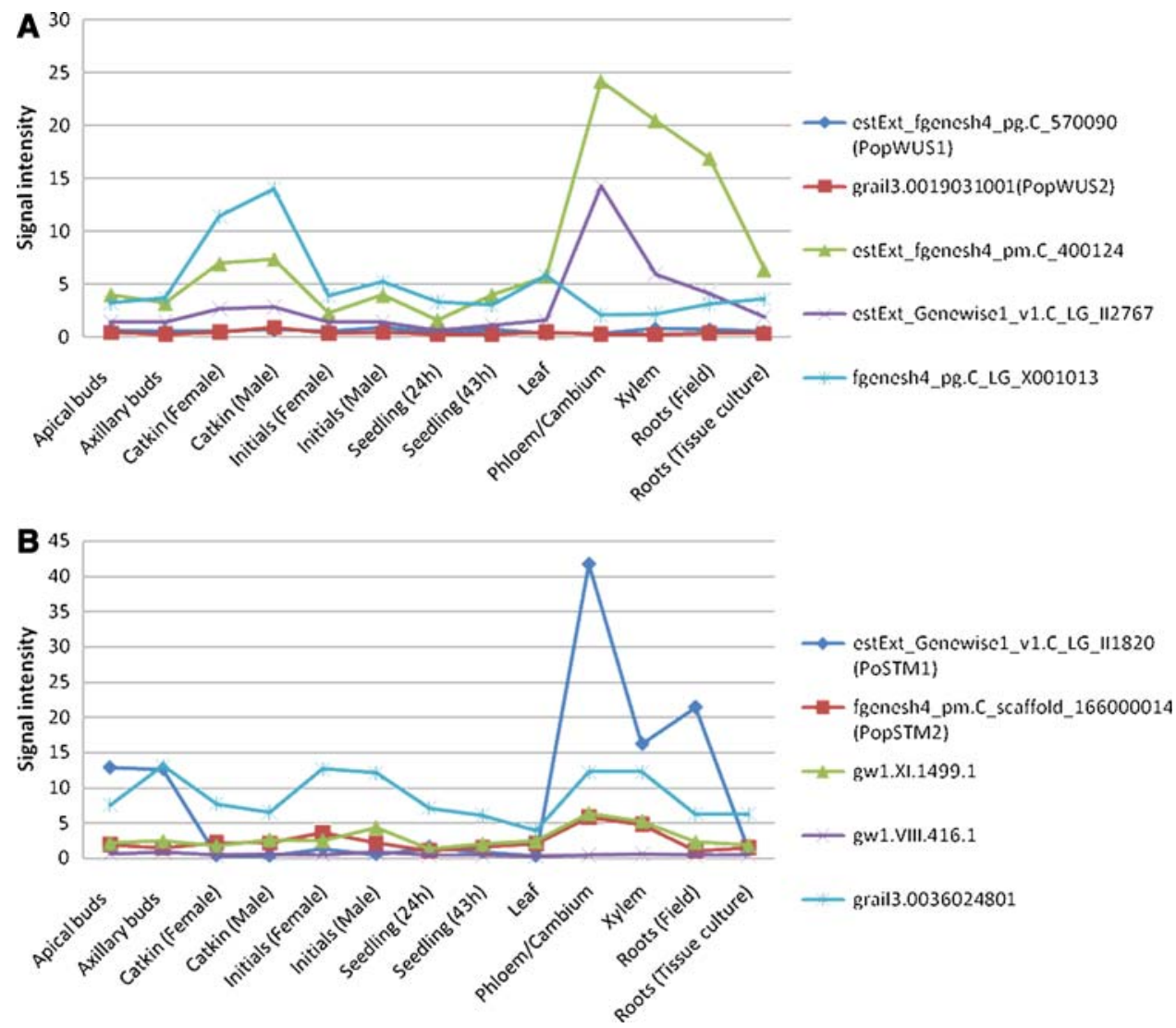

Table 3 Selected motifs related to cytokinin and auxin response from the Plant Cis-acting Regulatory DNA Elements (PLACE) database

\begin{tabular}{|c|c|c|c|c|c|}
\hline & PLACE ID & $\begin{array}{l}\text { PLACE accession } \\
\text { number }\end{array}$ & Sequence & Description & Selected references \\
\hline \multirow[t]{3}{*}{$\begin{array}{l}\text { Cytokinin } \\
\text { related }\end{array}$} & ARR1AT & S000454 & NGATT & $\begin{array}{l}\text { "ARR1-binding element" found in } \\
\text { Arabidopsis and rice; ARR1 is a } \\
\text { response regulator; } N=\mathrm{G} / \mathrm{A} / \mathrm{C} / \mathrm{T}\end{array}$ & Ross et al. (2004) \\
\hline & CPBCSPOR & S000491 & TATTAG & $\begin{array}{l}\text { Critical for cytokinin-enhanced } \\
\text { protein binding in vitro }\end{array}$ & Fusada, et al. (2005) \\
\hline & ARFAT(AuxRE) & S000270 & TGTCTC & $\begin{array}{l}\text { ARF binding site found in the } \\
\text { promoters of primary/early auxin } \\
\text { response genes }\end{array}$ & Goda et al. (2004) \\
\hline \multirow[t]{2}{*}{$\begin{array}{l}\text { Auxin } \\
\text { related }\end{array}$} & NTBBF1ARROLB & S000273 & ACTTTA & $\begin{array}{l}\text { Required for tissue-specific expression } \\
\text { and auxin induction }\end{array}$ & Baumann et al. (1999) \\
\hline & SURECOREATSULTR11 & S000499 & GAGAC & $\begin{array}{l}\text { Core of sulfur-responsive element } \\
\text { (SURE); containing ARF binding } \\
\text { sequence GAGACA } \\
\text { (complementary AuxRE TGTCTC) }\end{array}$ & $\begin{array}{l}\text { Maruyama-Nakashita } \\
\text { et al. (2005) }\end{array}$ \\
\hline
\end{tabular}

Two cytokinin-related and three auxin-related motifs were found in the promoter regions of WUS and STM genes from both Arabidopsis and poplar

critical for cytokinin-dependent protein binding in vitro (Fusada et al. 2005). ARFAT, also called AuxRE, is an auxin response factor (ARF) binding site found in the promoters of many primary/early auxin response genes of Arabidopsis such as small auxin-up RNA (SAUR) (Goda et al. 2004). NTBBF1ARROLB is the NtBBF1 (Dof protein from tobacco) binding site in regulatory domain $\mathrm{B}$ in
Agrobacterium, which is required for its tissue-specific expression and auxin response (Baumann et al. 1999). SURECOREATSULTR11 is the core of sulfur-responsive element (SURE) which contains the complementary sequence (TGTCTC) to the auxin response factor (ARF) binding sequence (GAGACA) (Maruyama-Nakashita et al. 2005). 


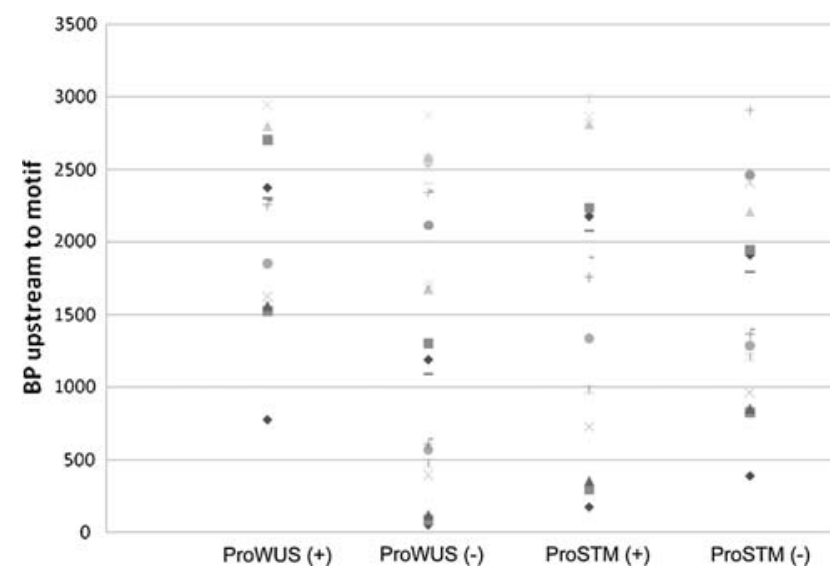

Fig. 11 Distribution of ARR1AT motifs in Arabidopsis WUS and STM promoters. The dots indicate the number of base pairs upstream of the translation initiation codons (ATGs) of WUS and STM; numbers are given for both $(+)$ and $(-)$ strand

The abundance of ARR1AT motifs supports their possible role as links between cytokinin signaling and meristem regulation. WUS has been found to repress ARR 5, 6, 7, and 15 by direct interaction with ARR7 (Leibfried et al. 2005). The abundance of ARR1ATs in the promoters of both WUS and STM suggests that ARR1 and its homologs in poplar are possible binding sites for cytokininimplying the direct regulation of WUS and STM activity by cytokinin.

WUS and STM have been cloned and characterized in several species in addition to Arabidopsis (Groover et al. 2006; Kamiya et al. 2003; Nardmann and Werr 2006). They function mainly in the SAM, and their closely related genes have similar roles of regulating meristems in the RAM and the secondary meristems. The dominant expression in shoot apical and axillary meristems seen in the transgenic plants demonstrates that the $3.5 \mathrm{~kb}$-promoters used to cover the majority of the elements needed for SAM regulatory functions, for which similar results were found in Arabidopsis (Baurle and Laux 2005; Uchida et al. 2007). A 57-bp regulatory region was sufficient there to provide all the information required for WUS transcription in the SAM. The activity could be further assigned to two adjacent short sequence motifs within the region (Baurle and Laux 2005).

In addition to the dominant expression in meristems, two other significant patterns we observed ( $>50 \%$ of transgenic events) in both WUS and STM transgenics was strong expression in leaf veins, and for WUS strong expression in hydathodes. Leaf veins are vascular tissues made up of xylem and phloem, and hydathodes are connected to the vascular tissues by a vascular bundle (Mauseth 1988). The $35 \mathrm{~S}$ enhancers present in the promoter used to drive the selectable marker gene in our vector may have broadened the variation in expression (Nilsson et al. 1992; Wei et al. 2007) beyond what would normally be produced due to position effects alone (Gallie 1998; van der Hoeven et al. 1994). However, the lack of preferential expression in hydathodes from the STM promoter-which was transformed using the same vector-makes it unlikely that the $35 \mathrm{~S}$ enhancers had a substantive influence. In addition, when the same poplar clones were transformed with enhancer trap vectors containing $35 \mathrm{~S}$ enhancers, the expression in hydathodes of the leaf was rare compared with other expression patterns (Groover et al. 2004). Finally, in ongoing studies in our laboratory (unpublished data) that used the same vector backbone and had gibberellic acid gene promoters (GA2-oxidase and GA20-oxidase) driving GUS in 26 independent events, the expression patterns seen were virtually all distinct from those seen in this study. This further shows that simple insertion of the GUS gene did not cause the meristem-, leaf vein-, and hydathode-dominant patterns seen with the WUS and/or STM promoters.

Table 4 Distribution of identified cytokinin-related and auxin-related PLACE motifs in WUS and STM genes from Arabidopsis and poplar

\begin{tabular}{|c|c|c|c|c|c|c|c|c|}
\hline & Motif ID & Strand & WUS & PopWUS1 & PopWUS2 & STM & PopSTM1 & PopSTM2 \\
\hline \multirow[t]{4}{*}{ Cytokinin related } & \multirow[t]{2}{*}{ ARR1AT } & $(+)$ & 13 & 9 & 7 & 14 & 17 & 7 \\
\hline & & $(-)$ & 22 & 14 & 14 & 16 & 5 & 10 \\
\hline & \multirow[t]{2}{*}{ CPBCSPOR } & $(+)$ & 1 & 0 & 2 & 2 & 0 & 0 \\
\hline & & $(-)$ & 4 & 1 & 2 & 0 & 0 & 0 \\
\hline \multirow[t]{6}{*}{ Auxin related } & \multirow[t]{2}{*}{ ARFAT(AuxRE) } & $(+)$ & 1 & 0 & 0 & 1 & 0 & 1 \\
\hline & & $(-)$ & 1 & 0 & 1 & 0 & 1 & 0 \\
\hline & \multirow[t]{2}{*}{ NTBBF1ARROLB } & $(+)$ & 0 & 3 & 6 & 3 & 0 & 4 \\
\hline & & $(-)$ & 5 & 1 & 3 & 2 & 0 & 4 \\
\hline & \multirow[t]{2}{*}{ SURECOREATSULTR11 } & $(+)$ & 1 & 3 & 3 & 0 & 1 & 1 \\
\hline & & $(-)$ & 6 & 2 & 2 & 1 & 1 & 5 \\
\hline
\end{tabular}

The numbers of the motifs are listed for the both strands of the promoters of both Arabidopsis and Populus WUS and STM

PopWUS1 = grail3_0019031001; PopWUS2 = estExt_fgenesh4_pg_C_570090

PopSTM1 = estExt_Genewise1_v1_C_LG_II1820; PopSTM2 = fgenesh4_pm_C_scaffold_166000014 
WUS and STM may take part in the precise spatial and temporal expression needed for differentiation of these organs. Veinal areas often show strong regeneration capacity in vitro, e.g., (Lee-Stadelmann et al. 1989). Microcross sections (MCS) of mid-veins from hybrid Populus leaves were approximately 25-fold more efficient in shoot regeneration than were entire explants. Perhaps, the common veinal patterns of GUS expression we observed with the WUS reporter genes was a result of cryptic meristematic tissues associated with leaf veins. Arabidopsis transformed with the promoter of an auxin-induced IAA gene from Zinnia that was driving GUS showed a very similar expression pattern in leaf veins to what we observed. This is not surprising given that WUS is certain to be responsive to auxin signaling cascades during organogenesis (Groover et al. 2003).

A hydathode is a type of secretory tissue that enables guttation, where water in the form of drops is released from the terminal tracheids of the veins and may help in transport of nutrients from roots to leaves. Hydathodes are primary sites of free-auxin production. The developmental pattern of free-auxin production is suggested to control the basipetal maturation sequence of leaf development and vascular differentiation in Arabidopsis leaves (Aloni et al. 2003). The pluripotency of hydathode cells is well known, most prominently in the Bryophyllum section of the succulent Kalanchoe, where miniature plantlets form on the margins of leaves and enable vegetative propagation (http://www.ars-grin.gov/cgi-bin/npgs/html/taxon.pl? 21076). The above evidence suggests that the expression of GUS in hydathodes conferred by the WUS promoter may be a result of WUS's regulatory role in auxin signaling and synthesis.

Although STM appears to have strong cambial expression based on array results, this was only modestly observed in the transgenic plants that we studied. This may be a result of their small size and limited secondary meristem development of the regenerated plants in GA-7 vessels (Magenta Corp.) when most events were GUS stained. We did observe expression during secondary growth in a subset of the STM::GUS transgenic poplars, but it was still visible in only a minority of transgenic events. For unknown reasons, similar to what we observed with the apical expression patterns from these promoters, the cambial expression patterns also show large variation in expression among transgenic events.

The efficient in vitro regeneration, propagation and transformation of woody plants remains a major obstacle to research and commercial applications (Nehra et al. 2005). There are a number of developmental obstacles that may exist-ranging from dedifferentiation to organ initiation-for which there is a lack of early morphological indicators. The transgenic reporter plants we developed would be useful for identifying very early stages of meristem initiation. Based on strong GUS activity for both the WUS and STM promoters that we observed in callus, this appears to be occurring during early callus development in poplar. GUS expression grew increasingly strong in calli over time, especially at the edges where shoots tend to emerge. The reporter, therefore, appeared to be active up to 2 weeks before shoot induction conditions were imposed via SIM medium, and several weeks before organ primordia become visible. Given the diverse expression patterns of WUS and STM gene family members in poplar revealed by our microarray analyses, it seems feasible to create reporter systems for other meristematic tissues using these promoters, particularly the vascular cambium and vein-associated pre-meristematic tissues.

Acknowledgments We would like to thank Rhonda Pham, and other high school and undergraduate student assistants working under Cathleen Ma, who performed transformation and in vitro propagation. We thank the USDA ARS Nursery and Floriculture Initiative, and the industrial members of the TBGRC Research Cooperative at Oregon State University for their support.

\section{References}

Aloni R, Schwalm K, Langhans M, Ullrich CI (2003) Gradual shifts in sites of free-auxin production during leaf-primordium development and their role in vascular differentiation and leaf morphogenesis in Arabidopsis. Planta 216:841-853

Arias RS, Filichkin SA, Strauss SH (2006) Divide and conquer: development and cell cycle genes in plant transformation. Trends Biotechnol 24:267-273

Bao Y (2008) Genome scale transcriptome analysis and development of reporter systems for studying shoot organogenesis in poplar. M.S. in genetics. Oregon State University, Corvallis

Baumann K, De Paolis A, Costantino P, Gualberti G (1999) The DNA binding site of the Dof protein NtBBF1 is essential for tissuespecific and auxin-regulated expression of the rolB oncogene in plants. Plant Cell 11:323-334

Baurle I, Laux T (2005) Regulation of WUSCHEL transcription in the stem cell niche of the Arabidopsis shoot meristem. Plant Cell 17:2271-2280

Bhalla PL, Singh MB (2006) Molecular control of stem cell maintenance in shoot apical meristem. Plant Cell Rep 25:249_ 256

Brunner AM, DiFazio SP, Crasta O, Fei Z, Mane SP, Sobral B, Dharmawardhana P (2007) Microarray expression analysis of poplar development. In: Plant and animal genomes XV conference, San Diego, CA, USA

Byrne ME, Kidner CA, Martienssen RA (2003) Plant stem cells: divergent pathways and common themes in shoots and roots. Curr Opin Genet Dev 13:551-557

Che P, Lall S, Nettleton D, Howell SH (2006) Gene expression programs during shoot, root, and callus development in Arabidopsis tissue culture. Plant Physiol 141:620-637

Filichkin SA, Meilan R, Busov VB, Ma C, Brunner AM, Strauss SH (2006) Alcohol-inducible gene expression in transgenic Populus. Plant Cell Rep 25:660-667 
Fusada N, Masuda T, Kuroda H, Shimada H, Ohta H, Takamiya K (2005) Identification of a novel cis-element exhibiting cytokinindependent protein binding in vitro in the $5^{\prime}$-region of NADPHprotochlorophyllide oxidoreductase gene in cucumber. Plant Mol Biol 59:631-645

Gallie DR (1998) Controlling gene expression in transgenics. Curr Opin Plant Biol 1:166-172

Goda H, Sawa S, Asami T, Fujioka S, Shimada Y, Yoshida S (2004) Comprehensive comparison of auxin-regulated and brassinosteroid-regulated genes in Arabidopsis. Plant Physiol 134:15551573

Groover AT (2005) What genes make a tree a tree? Trends Plant Sci 10:210-214

Groover AT, Pattishall A, Jones AM (2003) IAA8 expression during vascular cell differentiation. Plant Mol Biol 51:427-435

Groover A, Fontana JR, Dupper G, Ma C, Martienssen R, Strauss $S$, Meilan R (2004) Gene and enhancer trap tagging of vascular-expressed genes in poplar trees. Plant Physiol 134: $1742-1751$

Groover AT, Mansfield SD, DiFazio SP, Dupper G, Fontana JR, Millar R, Wang Y (2006) The Populus homeobox gene ARBORKNOX1 reveals overlapping mechanisms regulating the shoot apical meristem and the vascular cambium. Plant Mol Biol 61:917-932

Haecker A, Gross-Hardt R, Geiges B, Sarkar A, Breuninger H, Herrmann M, Laux T (2004) Expression dynamics of WOX genes mark cell fate decisions during early embryonic patterning in Arabidopsis thaliana. Development 131:657-668

Higo K, Ugawa Y, Iwamoto M, Korenaga T (1999) Plant cis-acting regulatory DNA elements (PLACE) database: 1999. Nucleic Acids Res 27:297-300

Jansson S, Douglas CJ (2007) Populus: a model system for plant biology. Annu Rev Plant Biol 58:435-458

Kamiya N, Nagasaki H, Morikami A, Sato Y, Matsuoka M (2003) Isolation and characterization of a rice WUSCHEL-type homeobox gene that is specifically expressed in the central cells of a quiescent center in the root apical meristem. Plant J 35:429-441

Laux T (2003) The stem cell concept in plants: a matter of debate. Cell 113:281-283

Laux T, Mayer KF, Berger J, Jurgens G (1996) The WUSCHEL gene is required for shoot and floral meristem integrity in Arabidopsis. Development 122:87-96

Lee-Stadelmann OY, Lee SW, Hackett WP (1989) The formation of adventitious buds in vitro on micro-cross sections of hybrid Populus leaf midveins. Plant Sci 61:263-272

Leibfried A, To JP, Busch W, Stehling S, Kehle A, Demar M, Kieber JJ, Lohmann JU (2005) WUSCHEL controls meristem function by direct regulation of cytokinin-inducible response regulators. Nature 438:1172-1175

Long JA, Moan EI, Medford JI, Barton MK (1996) A member of the KNOTTED class of homeodomain proteins encoded by the STM gene of Arabidopsis. Nature 379:66-69

Maruyama-Nakashita A, Nakamura Y, Watanabe-Takahashi A, Inoue E, Yamaya T, Takahashi H (2005) Identification of a novel cisacting element conferring sulfur deficiency response in Arabidopsis roots. Plant J 42:305-314

Mauseth JD (1988) Plant anatomy. Addison Wesley/Benjamin Cummings, San Francisco

Mayer KF, Schoof H, Haecker A, Lenhard M, Jurgens G, Laux T (1998) Role of WUSCHEL in regulating stem cell fate in the Arabidopsis shoot meristem. Cell 95:805-815

Nardmann J, Werr W (2006) The shoot stem cell niche in angiosperms: expression patterns of $W U S$ orthologues in rice and maize imply major modifications in the course of mono- and dicot evolution. Mol Biol Evol 23:2492-2504
Nehra N, Becwar M, Rottmann W, Pearson L, Chowdhury K, Chang S, Dayton Wilde H, Kodrzycki R, Zhang C, Gause K, Parks D, Hinchee M (2005) Forest biotechnology: innovative methods, emerging opportunities. In Vitro Cell Dev Biol Plant 41:701-717

Nilsson O, Aldén T, Sitbon F, Anthony Little C, Chalupa V, Sandberg G, Olsson O (1992) Spatial pattern of cauliflower mosaic virus $35 \mathrm{~S}$ promoter-luciferase expression in transgenic hybrid aspen trees monitored by enzymatic assay and non-destructive imaging. Transgenic Res 1:209-220

Ross EJ, Stone JM, Elowsky CG, Arredondo-Peter R, Klucas RV, Sarath G (2004) Activation of the Oryza sativa non-symbiotic haemoglobin-2 promoter by the cytokinin-regulated transcription factor, ARR1. J Exp Bot 55:1721-1731

Schrader J, Nilsson J, Mellerowicz E, Berglund A, Nilsson P, Hertzberg M, Sandberg G (2004) A high-resolution transcript profile across the wood-forming meristem of poplar identifies potential regulators of cambial stem cell identity. Plant Cell 16:2278-2292

Scofield S, Murray JA (2006) The evolving concept of the meristem. Plant Mol Biol 60:V-VII

Sterky F, Bhalerao RR, Unneberg P, Segerman B, Nilsson P, Brunner AM, Charbonnel-Campaa L, Lindvall JJ, Tandre K, Strauss SH, Sundberg B, Gustafsson P, Uhlen M, Bhalerao RP, Nilsson O, Sandberg G, Karlsson J, Lundeberg J, Jansson S (2004) A Populus EST resource for plant functional genomics. Proc Natl Acad Sci USA 101:13951-13956

Tamura K, Dudley J, Nei M, Kumar S (2007) MEGA4: Molecular Evolutionary Genetics Analysis (MEGA) software version 4.0. Mol Biol Evol 24:1596-1599

Tuskan GA, Difazio S, Jansson S, Bohlmann J, Grigoriev I, Hellsten U, Putnam N, Ralph S, Rombauts S, Salamov A, Schein J, Sterck L, Aerts A, Bhalerao RR, Bhalerao RP, Blaudez D, Boerjan W, Brun A, Brunner A, Busov V, Campbell M, Carlson J, Chalot M, Chapman J, Chen GL, Cooper D, Coutinho PM, Couturier J, Covert S, Cronk Q, Cunningham R, Davis J, Degroeve S, Dejardin A, Depamphilis C, Detter J, Dirks B, Dubchak I, Duplessis S, Ehlting J, Ellis B, Gendler K, Goodstein D, Gribskov M, Grimwood J, Groover A, Gunter L, Hamberger B, Heinze B, Helariutta Y, Henrissat B, Holligan D, Holt R, Huang $\mathrm{W}$, Islam-Faridi N, Jones S, Jones-Rhoades M, Jorgensen R, Joshi C, Kangasjarvi J, Karlsson J, Kelleher C, Kirkpatrick R, Kirst M, Kohler A, Kalluri U, Larimer F, Leebens-Mack J, Leple JC, Locascio P, Lou Y, Lucas S, Martin F, Montanini B, Napoli C, Nelson DR, Nelson C, Nieminen K, Nilsson O, Pereda V, Peter G, Philippe R, Pilate G, Poliakov A, Razumovskaya J, Richardson P, Rinaldi C, Ritland K, Rouze P, Ryaboy D, Schmutz J, Schrader J, Segerman B, Shin H, Siddiqui A, Sterky F, Terry A, Tsai CJ, Uberbacher E, Unneberg P, Vahala J, Wall K, Wessler S, Yang G, Yin T, Douglas C, Marra M, Sandberg G, Van de Peer Y, Rokhsar D (2006) The genome of black cottonwood, Populus trichocarpa (Torr. \& Gray). Science 313:1596-1604

Uchida N, Townsley B, Chung KH, Sinha N (2007) Regulation of SHOOT MERISTEMLESS genes via an upstream-conserved noncoding sequence coordinates leaf development. Proc Natl Acad Sci USA 104:15953-15958

van der Hoeven C, Dietz A, Landsmann J (1994) Variability of organspecific gene expression in transgenic tobacco plants. Transgenic Res 3:159-166

Vernoux T, Benfey PN (2005) Signals that regulate stem cell activity during plant development. Curr Opin Genet Dev 15:388-394

Wang X, He H, Li L, Chen R, Deng XW, Li S (2006) NMPP: a usercustomized NimbleGen microarray data processing pipeline. Bioinformatics 22:2955-2957 
Wei H, Meilan R, Brunner A, Skinner J, Ma C, Gandhi H, Strauss S (2007) Field trial detects incomplete barstar attenuation of vegetative cytotoxicity in Populus trees containing a poplar $L E A F Y$ promoter::barnase sterility transgene. Mol Breed 19:69-85
Weigel D, Glazebrook J (2002) Arabidopsis: a laboratory manual. Cold Spring Harbor Laboratory Press, Cold Spring Harbor Williams L, Fletcher JC (2005) Stem cell regulation in the Arabidopsis shoot apical meristem. Curr Opin Plant Biol 8:582-586 


\section{Electronic Supplemental Materials}

S1. Sequences of primers used in cloning of the promoters of WUS and STM.

S2. Map of PopWUS1:: GUSPlus binary vector.

S3. Map of PopSTM1::GUSPlus binary vector.

S4. Transformation efficiency of PopWUS1:: GUSPlus and PopSTM1:: GUSPlus transgenic events. Overall transformation efficiency is the percentage of explants cocultivated that gave rise to an independent transgenic plant.

S5. Expression patterns of all PopWUS1:: GUSPlus transgenic events. Entire regenerated plants from all 45 PCR positive PopWUS1:: GUSPlus transgenic events were GUS stained, and their expression patterns summarized. A darkened box indicates observed expression in that tissue/organ.

S6. Expression patterns of PopSTM1:: GUSPlus transgenic events. Entire regenerated plants of all 54 PopSTM1:: GUSPlus transgenic events were GUS stained and their expression patterns summarized. A darkened box indicates observed expression in that tissue/organ.

S7. Affymetrix probe sets targeting WUS, STM and closely related poplar genes. The number of probe sets (of the 11 per gene on the array with a perfect match to the gene models), are listed. Expression from each probe set at the five sample points during regeneration is given in the rightmost columns. 
S1

\begin{tabular}{ll}
\hline Primer ID & Sequence \\
\hline WUS2proForward & 5' CGGCTGGGCAATATCACTAATAG 3' \\
WUS2proReverse & 5' GATGGATTGAGAAGCCAGAAC 3' \\
WUSpro1 & 5' ATGATGAAGTGTCAAACTCAA 3' \\
WUSpro2 & 5' AACCTGGTAGTAAATCATGCAC 3' \\
WUSpro3 & 5' TGAACCCAATTGCCGACATTAC 3' \\
WUSpro4 & 5' TATGATCAGGGAGCAAGAGATG 3' \\
WUSpro5 & 5' AGACATGAACACACTACATCG 3' \\
\hline STM3pro-F03 & 5' ACGAGCTCTCATGCTACTGGTAACCCTT 3' \\
STM3pro-R01 & 5' TAGGTACCCTCTCTCGACAAACCCAGTT 3' \\
STMinternal\#1 & 5' GTCAAGGATTTATTGCAAGAGT 3' \\
STMinternal\#2 & 5' GTTAGGATAGAAAAAAGATCAT 3' \\
STMinternal\#3 & 5' ATTTTTATTATAGATTAGTTTT 3' \\
STMinternal\#4 & 5' ATCCAGTTTGTGCGCACCTCGA 3' \\
STMinternal\#5 & 5'AGTAGAGAATGTTTTATATCCA 3' \\
\hline GPLUS287R & 5' AGTCCTTTCCCGTAGTCC 3' \\
KNX91F & 5' CACCAAGAAACGCAGCCCTTAG 3' \\
\hline
\end{tabular}




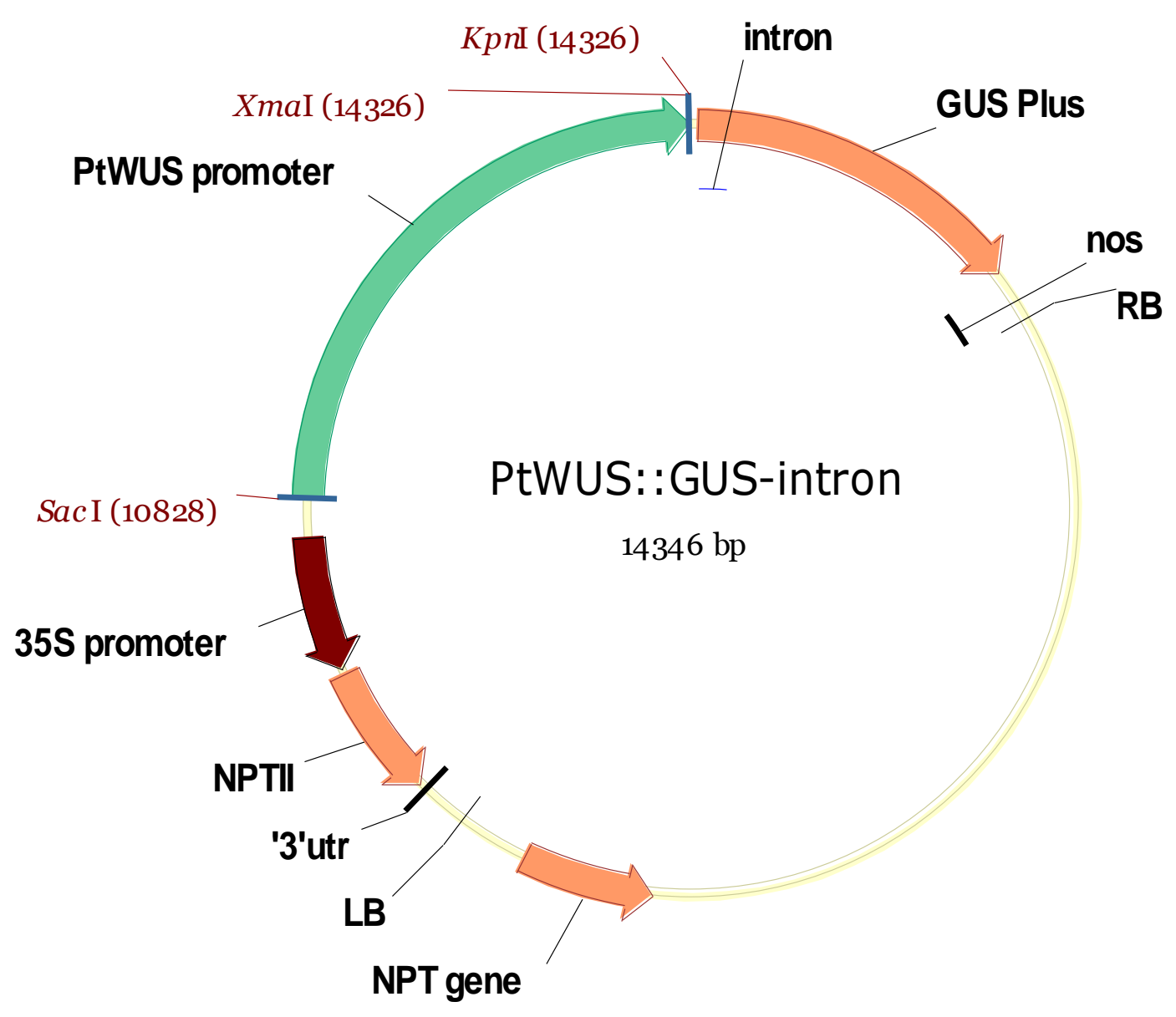


S3

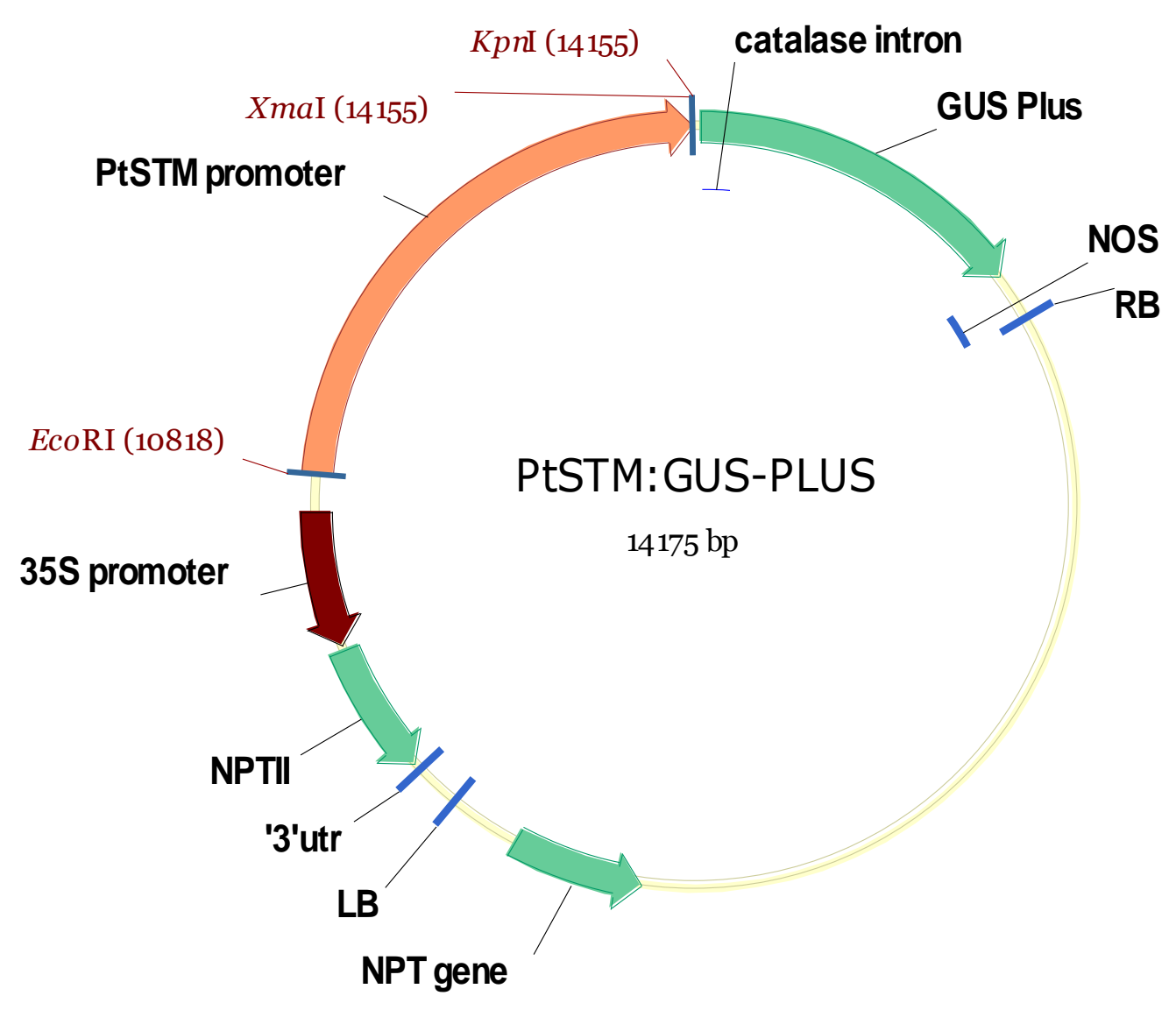


S4

\begin{tabular}{lll}
\hline Construct & ProWUS1::GUSPlus & ProSTM1::GUSPlus \\
\hline No. of explants co-cultivated & 2,066 & 1,976 \\
No. of explants with shoots & 259 & 281 \\
No. of shoots selected & 145 & 176 \\
No. of shoots rooted & 68 & 80 \\
No. of plants PCR positive & 47 & 59 \\
Overall transformation efficiency & $2.27 \%$ & $2.99 \%$ \\
\hline
\end{tabular}




\begin{tabular}{|c|c|c|c|c|c|c|c|c|c|}
\hline \multirow[b]{3}{*}{ Populus WUS } & \multicolumn{7}{|c|}{ Expression location } & \multirow[b]{3}{*}{$\begin{array}{c}\text { Number } \\
\text { of events }\end{array}$} & \multirow[b]{3}{*}{ Percentage } \\
\hline & \multirow{2}{*}{$\begin{array}{l}\text { Apical and } \\
\text { axillary } \\
\text { meristems }\end{array}$} & \multicolumn{4}{|c|}{ Other aerial } & \multicolumn{2}{|c|}{ Subaerial } & & \\
\hline & & Hydathodes & $\begin{array}{c}\text { Leaf lamina } \\
\& \text { veins }\end{array}$ & $\begin{array}{c}\text { Leaf lamina } \\
\& \text { petioles }\end{array}$ & Stipules & Root tips & Other & & \\
\hline & & & & & & & & 9 & $20.0 \%$ \\
\hline & & & & & & & & 3 & $6.7 \%$ \\
\hline & & & & & & & & 3 & $6.7 \%$ \\
\hline & & & & & & & & 3 & $6.7 \%$ \\
\hline & & & & & & & & 1 & $2.2 \%$ \\
\hline & & & & & & & & 1 & $2.2 \%$ \\
\hline & & & & & & & & 1 & $2.2 \%$ \\
\hline & & & & & & & & 1 & $2.2 \%$ \\
\hline & & & & & & & & 1 & $2.2 \%$ \\
\hline & & & & & & & & 1 & $2.2 \%$ \\
\hline & & & & & & & & 1 & $2.2 \%$ \\
\hline & & & & & & & & 1 & $2.2 \%$ \\
\hline & & & & & & & & 1 & $2.2 \%$ \\
\hline & & & & & & & & 1 & $2.2 \%$ \\
\hline & & & & & & & & 1 & $2.2 \%$ \\
\hline & & & & & & & & 1 & $2.2 \%$ \\
\hline & & & & & & & & 1 & $2.2 \%$ \\
\hline & & & & & & & & 1 & $2.2 \%$ \\
\hline & & & & & & & & 1 & $2.2 \%$ \\
\hline & & & & & & & & 1 & $2.2 \%$ \\
\hline & & & & & & & & 1 & $2.2 \%$ \\
\hline & & & & & & & & 1 & $2.2 \%$ \\
\hline & & & & & & & & 1 & $2.2 \%$ \\
\hline & & & & & & & & 1 & $2.2 \%$ \\
\hline & & & & & & & & 1 & $2.2 \%$ \\
\hline & & & & & & & & 1 & $2.2 \%$ \\
\hline & & & & & & & & 1 & $2.2 \%$ \\
\hline
\end{tabular}




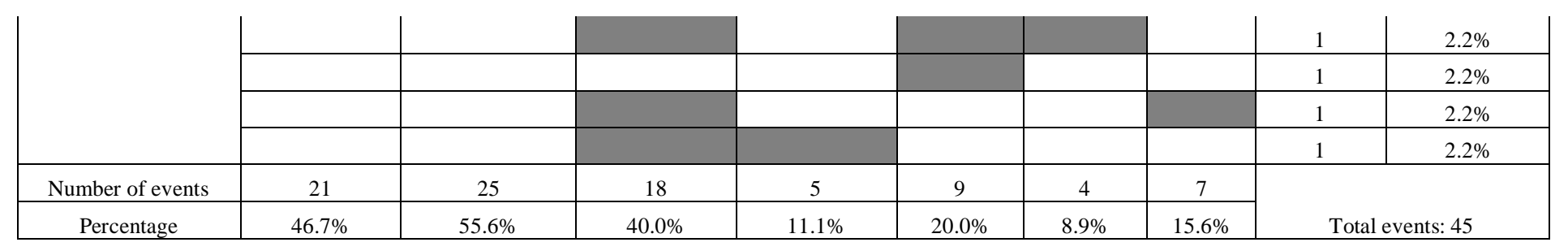




\section{S6}

\begin{tabular}{|c|c|c|c|c|c|c|c|c|c|}
\hline \multirow[b]{3}{*}{ Populus STM } & \multicolumn{7}{|c|}{ Expression location } & \multirow[b]{3}{*}{$\begin{array}{c}\text { Number of } \\
\text { events }\end{array}$} & \multirow[b]{3}{*}{ Percentage } \\
\hline & \multirow{2}{*}{$\begin{array}{c}\text { Apical - } \\
\text { axillary } \\
\text { meristems }\end{array}$} & \multicolumn{4}{|c|}{ Other aerial } & \multicolumn{2}{|c|}{ Subaerial } & & \\
\hline & & Hydathodes & $\begin{array}{c}\text { Leaf lamina } \\
\text { \& veins }\end{array}$ & $\begin{array}{c}\text { Leaf lamina } \\
\& \text { petiole }\end{array}$ & Stipules & Root tips & Other & & \\
\hline & & & & & & & & 13 & $24.1 \%$ \\
\hline & & & & & & & & 11 & $20.4 \%$ \\
\hline & & & & & & & & 5 & $9.3 \%$ \\
\hline & & & & & & & & 2 & $3.7 \%$ \\
\hline & & & & & & & & 2 & $3.7 \%$ \\
\hline & & & & & & & & 1 & $1.9 \%$ \\
\hline & & & & & & & & 1 & $1.9 \%$ \\
\hline & & & & & & & & 1 & $1.9 \%$ \\
\hline & & & & & & & & 1 & $1.9 \%$ \\
\hline & & & & & & & & 1 & $1.9 \%$ \\
\hline & & & & & & & & 1 & $1.9 \%$ \\
\hline & & & & & & & & 1 & $1.9 \%$ \\
\hline & & & & & & & & 1 & $1.9 \%$ \\
\hline & & & & & & & & 1 & $1.9 \%$ \\
\hline & & & & & & & & 1 & $1.9 \%$ \\
\hline & & & & & & & & 1 & $1.9 \%$ \\
\hline & & & & & & & & 1 & $1.9 \%$ \\
\hline & & & & & & & & 1 & $1.9 \%$ \\
\hline & & & & & & & & 1 & $1.9 \%$ \\
\hline & & & & & & & & 1 & $1.9 \%$ \\
\hline & & & & & & & & 1 & $1.9 \%$ \\
\hline & & & & & & & & 1 & $1.9 \%$ \\
\hline & & & & & & & & 1 & $1.9 \%$ \\
\hline & & & & & & & & 1 & $1.9 \%$ \\
\hline & & & & & & & & 1 & $1.9 \%$ \\
\hline & & & & & & & & 1 & $1.9 \%$ \\
\hline Number of events & 35 & 5 & 25 & 9 & 6 & 12 & 14 & & \\
\hline Percentage & $64.8 \%$ & $9.3 \%$ & $46.3 \%$ & $16.7 \%$ & $11.1 \%$ & $22.2 \%$ & $25.9 \%$ & & 54 \\
\hline
\end{tabular}


S7

\begin{tabular}{|c|c|c|c|c|c|c|c|c|}
\hline & \multirow[b]{2}{*}{ Affymetrix probe set ID } & \multirow[b]{2}{*}{ Poplar gene model } & \multicolumn{6}{|c|}{ Expression values } \\
\hline & & & $\begin{array}{c}\text { Number } \\
\text { matching probes }\end{array}$ & Pre-induction & 3d CIM & $15 \mathrm{~d}$ CIM & 3d SIM & $8 \mathrm{~d}$ SIM \\
\hline \multirow{8}{*}{ WUS } & PtpAffx.218777.1.S1_s_at & grail3.0019031001(PopWUS1) & 11 & 2.72 & 2.66 & 2.77 & 5.23 & 5.55 \\
\hline & PtpAffx.207414.1.S1_at & grail3.0019031001(PopWUS1) & 11 & 2.15 & 2.14 & 2.16 & 2.20 & 2.15 \\
\hline & PtpAffx.218777.1.S1_s_at & estExt_fgenesh4_pg.C_570090 (PopWUS2) & 9 & 2.72 & 2.66 & 2.77 & 5.23 & 5.55 \\
\hline & PtpAffx.54684.1.A1_at & estExt_fgenesh4_pg.C_570090 (PopWUS2) & 7 & 2.23 & 2.19 & 2.21 & 4.38 & 5.01 \\
\hline & PtpAffx.5866.1.A1_a_at & estExt_fgenesh4_pm.C_400124 & 11 & 10.24 & 10.99 & 7.46 & 10.27 & 9.58 \\
\hline & PtpAffx.208881.1.S1_at & fgenesh4_pg.C_LG_X001013 & 11 & 2.23 & 2.22 & 2.23 & 2.29 & 2.23 \\
\hline & PtpAffx.218777.1.S1_s_at & gw1.21516.1.1 (truncated) & 11 & 2.72 & 2.66 & 2.77 & 5.23 & 5.55 \\
\hline & no match & estExt_Genewise1_v1.C_LLG_II2767 & 0 & & & & & \\
\hline \multirow{5}{*}{ STM } & Ptp.5813.1.S1_at & estExt_Genewise1_v1.C_LG_II1820 (PopSTM1) & 11 & 12.49 & 9.89 & 10.42 & 10.02 & 9.51 \\
\hline & Ptp.5742.1.S1_at & grail3.0036024801 & 11 & 10.78 & 9.18 & 8.96 & 9.44 & 7.96 \\
\hline & PtpAffx.3110.1.S1_at & gw1.XI.1499.1(truncated) & 5 & 11.37 & 8.00 & 7.63 & 7.68 & 7.81 \\
\hline & PtpAffx.3110.2.S1_at & fgenesh4_pm.C_scaffold_166000014 (PopSTM2) & 3 & 9.34 & 6.35 & 2.87 & 2.95 & 2.84 \\
\hline & PtpAffx.20353.1.A1_s_at & gw1.VIII.416.1 & 2 & 10.30 & 9.17 & 8.59 & 8.93 & 7.95 \\
\hline
\end{tabular}

